\title{
A Review of Thermal and Optical Characterisation of Complex Window Systems and Their Building Performance Prediction
}

\author{
Yanyi Sun, Yupeng Wu* and Robin Wilson
}

\begin{abstract}
Department of Architecture and Built Environment, Faculty of Engineering, The University of Nottingham, University Park, Nottingham, NG7 2RD, UK
\end{abstract}

*Corresponding author: Tel: +44 (0) 11574 84011; emails: Yupeng.Wu@nottingham.ac.uk, Jackwuyp@googlemail.com

\begin{abstract}
:
Window systems play a key role in establishing both the thermal and luminous environments within buildings, as well as the consequent energy required to maintain these for the comfort of their occupants. Various strategies have been employed to improve the thermal and optical performance of window systems. Some of these approaches result in products with relatively complex structures. Thus, it becomes difficult to characterise their optical and thermal properties for use in building performance prediction. This review discusses the experimental and numerical methods used to predict the thermal and optical behaviour of complex window systems. Following a discussion of thermal characterisation methods available in the literature that include experimental test methods, theoretical calculation methods and Computational Fluid Dynamic methods, sophisticated optical methods, such as use of Bidirectional Scatter Distribution Functions (BSDF) to optically characterise complex window systems, are introduced. The application of BSDF allows advanced daylight assessment metrics along with daylight evaluation tools to be used to realise dynamic annual prediction of the luminous environment. Finally, this paper reviews methods that permit the prediction of the combined thermal, daylight and energy behaviour of buildings that make use of complex window systems.
\end{abstract}

\section{Keywords:}

Complex window systems; Thermal Performance; Bidirectional Scatter Distribution Functions (BSDF); Daylight Performance; Building Modelling. 


\section{Nomenclature}

\section{Symbols}

$c_{p} \quad$ specific heat capacity

Const. constant

$d$ thickness of glass pane

$D_{\lambda} \quad$ spectral distribution

$e$ exponent

$E_{v} \quad$ vertical eye illuminance

$E_{o}$ exterior IR incident on

window plane

$E_{i} \quad$ interior IR incident on

window plane

$F \quad$ view factor

$g$ gravitational acceleration

$h$ heat transfer coefficient

- also thermal conductance

$J$ radiosity

$k \quad$ thermal conductivity

$L_{s} \quad$ luminance of source

$N$ number

$p$ pressure

$P \quad$ position index

$q$ heat flux

$R \quad$ thermal resistance

$S \quad$ thickness of the window air cavity

$S_{h} \quad$ radiative heat transfer

$S_{i} \quad$ radiation (short-wave, and long-wave from zone internal sources) absorbed by face $i$

$T$ temperature

$U$ thermal transmittance

$u, v \quad$ velocity components

$\begin{array}{rclr}\mathrm{J} / \mathrm{kgK} & v & \text { kinematic viscosity } & \mathrm{m}^{2} / \mathrm{s} \\ - & V(\lambda) & \text { spectral luminous efficiency } & - \\ \mathrm{m} & & \text { for photonic vision } & \\ - & x, y & \text { Cartesian coordinates } & - \\ - & \Delta T & \text { temperature difference } & \mathrm{K} \\ \operatorname{lux} & \Delta \lambda & \text { wavelength interval } & \mathrm{nm} \\ \mathrm{W} / \mathrm{m}^{2} & \beta & \text { thermal expansion coefficient } & 1 / \mathrm{K} \\ & \varepsilon & \text { Emissivity } & - \\ \mathrm{W} / \mathrm{m}^{2} & \sigma & \text { Stefan-Boltzmann constant } & \mathrm{W} / \mathrm{m}^{2} \mathrm{~K}^{4} \\ & \theta & \text { incidence angle } & \circ \\ - & \varphi & \text { azimuth angle } & \circ \\ \mathrm{m} / \mathrm{s}^{2} & \lambda & \text { wavelength } & \mathrm{nm} \\ \mathrm{W} / \mathrm{m}^{2} \mathrm{~K} & \tau & \text { transmittance } & - \\ \mathrm{W} / \mathrm{m}^{2} \mathrm{~K} & \mu & \text { dynamic viscosity of gas } & \mathrm{kg} / \mathrm{ms} \\ \mathrm{W} / \mathrm{m}^{2} & \rho & \text { density of air } & \mathrm{kg} / \mathrm{m}^{3} \\ \mathrm{~W} / \mathrm{mK} & \omega_{S} & \text { solid angle } & \mathrm{sr}\end{array}$

$\mathrm{cd} / \mathrm{m}^{2}$

- Dimensionless Numbers

$\mathrm{Pa} \quad G r \quad$ Grashof number

$\mathrm{Nu} \quad$ Nusselt number

$\mathrm{W} / \mathrm{m}^{2} \quad \mathrm{Pr} \quad$ Prandtl number

$\mathrm{mK} / \mathrm{W}$

m Subscripts

e external

$g$ gas

$\mathrm{W} / \mathrm{m}^{2} \quad p \quad$ glass pane

$H$ hot

$i$ internal

$i, j, k$ counter

${ }^{\circ} \mathrm{C} m$ mean

$\mathrm{W} / \mathrm{m}^{2} \mathrm{~K} \quad t \quad$ total

$r$ radiation

\section{Introduction}

Windows in building envelopes are critical components that determine direct solar energy gains and daylight, facilitate the view into and out of a building, and influence overall building energy consumption [1-3]. However, the material properties of glass when used in conventional windows arouse concerns in response to the recent sustainability agenda, in particular in relation to the responsible use of energy in buildings. The most common issues are:

1) Overheating during the hot season resulting in high cooling loads due to significant direct solar gain through window systems [4-6]; 
2) Significant heat loss during cold seasons due to the relatively high $U$-value compared with walls or ceilings [7-12];

3) Visual discomfort from glare in work spaces [13-15];

4) Glare caused by the reflection of sunlight from glazing to a buildings immediate surroundings or the city more widely [16];

5) Air infiltration through defects between glazing and frame due to poor workmanship [17, $18]$

6) Degradation and fading of building components or furniture due to the presence of high levels of transmitted sunlight in the internal environment $[19,20]$.

Improvements to the design and manufacture of window systems seek to optimise the effective use of solar resource, minimise undesired energy losses and effectively moderate the indoor environment. The two main strategies that have been applied are: 1) increasing thermal resistance using approaches such as multiple glass panes, inert gases as cavity fill, low emissivity coatings, and vacuum glazing; 2) controlling solar radiation and daylight through application of tinted coatings, reflective coatings, interstitial shading devices, and smart window techniques (e.g. electrochromic, thermochromic, photochromic glazing). Some of these approaches result in window systems with relatively complex structures, which increases the challenge of accurately characterising their behaviour for use in studies of building performance. The process of characterisation for these complex glazing systems involves investigations that explore and quantify both their thermal and optical behaviours. There is little in the literature, however, that reviews these methods of characterisation or explores their use to inform the predicted performance of buildings employing these systems. This review will play a critical role in addressing these challenges and suggest ways in which they might be used to inform the future application of novel and complex window systems to buildings.

This paper starts by reviewing the experimental and numerical methods used to evaluate the thermal characteristics of glazing systems with complex interstitial structures. It also describes the experimental and numerical methods used to quantify the optical performance of glazing with interstitial structures, the advanced daylight assessment metrics used to assess the annual performance of spaces served by these systems, and the simulation tools that may be used to evaluate these metrics. The last section, this paper reviews methods 
that permit the prediction of the combined thermal, daylight and energy behaviour of spaces served by complex window systems.

\section{Thermal investigations of window systems}

In this section, the experimental and numerical methods that can be used to evaluate the thermal properties of a building component, with a focus on window systems with complex structures, is introduced and discussed.

\subsection{Experimental investigation methods}

There are established international and national standards for measuring the thermal properties (i.e. thermal transmittance, thermal conductance, thermal resistance and U-value) of a window system. The guarded hot-plate method, heat flow meter method and guarded or calibrated hot-box method are three key approaches for measuring steady-state thermal properties under laboratory conditions. The dynamic thermal properties of building components, measured under more realistic environmental conditions, can be determined using heat flux meters in in-situ measurements. The international and national standards for these steady state and dynamic methods are listed in Table 1. 
Table 1: Standards for determining thermal properties using experimental methods

\begin{tabular}{|c|c|c|c|}
\hline Region & Name & Title & Method \\
\hline \multirow{5}{*}{ International } & $\begin{array}{l}\text { ISO } 12567 \\
{[21]}\end{array}$ & $\begin{array}{l}\text { Thermal performance of windows and doors - } \\
\text { Determination of thermal transmittance by the hot- } \\
\text { box method - Part 1: Complete windows and doors }\end{array}$ & Hot-box \\
\hline & $\begin{array}{l}\text { ISO } 9869 \\
{[22]}\end{array}$ & $\begin{array}{l}\text { Thermal insulation - Building elements - In-situ } \\
\text { measurement of thermal resistance and thermal } \\
\text { transmittance Part1: Heat flow meter method }\end{array}$ & In-situ \\
\hline & $\begin{array}{l}\text { ISO } 8990 \\
{[23]}\end{array}$ & $\begin{array}{l}\text { Thermal insulation - Determination of steady-state } \\
\text { thermal transmission properties - Calibrated and } \\
\text { guarded hot box }\end{array}$ & Hot-box \\
\hline & $\begin{array}{l}\text { ISO } 8301 \\
{[24]}\end{array}$ & $\begin{array}{l}\text { Thermal insulation - Determination of steady-state } \\
\text { thermal resistance and related properties - Heat } \\
\text { flow meter apparatus }\end{array}$ & $\begin{array}{l}\text { Heat flow } \\
\text { meter }\end{array}$ \\
\hline & $\begin{array}{l}\text { ISO } 8302 \\
{[25]}\end{array}$ & $\begin{array}{l}\text { Thermal insulation - Determination of steady-state } \\
\text { thermal resistance and related properties - Guarded } \\
\text { hot plate apparatus }\end{array}$ & Hot-plate \\
\hline \multirow{3}{*}{ USA } & $\begin{array}{l}\text { ASTM } \\
\text { C1363 [26] }\end{array}$ & $\begin{array}{l}\text { Standard test method for thermal performance of } \\
\text { building materials and envelope assemblies } \\
\text { by means of a hot box apparatus }\end{array}$ & Hot-box \\
\hline & $\begin{array}{l}\text { ASTM } \\
\text { C1199 [27] }\end{array}$ & $\begin{array}{l}\text { Standard test method for measuring the steady- } \\
\text { state thermal transmittance of fenestration } \\
\text { systems using hot box methods }\end{array}$ & Hot-box \\
\hline & $\begin{array}{l}\text { ASTM } \\
\text { C1046 [28] }\end{array}$ & $\begin{array}{l}\text { Standard practice for in-situ measurement of heat } \\
\text { flux and temperature on building envelope } \\
\text { components }\end{array}$ & In-Situ \\
\hline
\end{tabular}

EN 674 Glass in building-Determination of thermal Hot-plate

[29] transmittance (U value)-Guarded hot plate method

EN 675 Glass in building-Determination of thermal Heat flow [30] transmittance (U value)-Heat flow meter method meter

Europe $\quad$ EN 1946-2 Thermal performance of building products and Hot-plate

[31] components. Specific criteria for the assessment of 
laboratories measuring heat transfer properties.

Measurements by guarded hot plate method

EN 1946-3 Thermal performance of building products and Heat flow

components - Specific criteria for the assessment meter

of laboratories measuring heat transfer

properties-Part 3: Measurements by heat flow

meter method

\begin{tabular}{llll}
\hline Russian & GOST & $\begin{array}{l}\text { Windows and doors. Methods of determination of } \\
\text { 26602.1 [33] }\end{array}$ & resistance of thermal transmission
\end{tabular}

The three steady state laboratory measurement approaches share the same concept: a fixed temperature gradient is established between two sides of the test sample and the heat flow across the sample is determined. Schematic diagrams for these three approaches are shown in Figure 1. The guarded hot-plate apparatus [25, 29, 31] as shown in Figure 1(a) consists of two nearly identical test specimens, a heating unit, enclosed by the specimens and a thermally isolated guard area, and two cooling units located on the outer sides of the specimens. The DC-power supplied to the heating unit is varied until the desired mean temperature of each specimen (i.e. $10 \pm 0.5^{\circ} \mathrm{C}$ ) and the desired temperature difference between the hot and cold surfaces of the specimens (i.e. $15 \pm 0.5 \mathrm{~K}$ ) are achieved. The measured DC-power is then used to determine the thermal transmittance through the specimen. As shown in Figure 1 (b), the heat flow meter measurement method [24, 30, 32] is similar to that of the hot-plate method, as the specimen is sandwiched between heating and cooling units. Instead of measuring the supplied DC-power, the heat flow densities (in $\mathrm{W} / \mathrm{m}^{2}$ ) are measured using calibrated heat flux meters coupled to the surfaces of the specimen. By selecting a sample with sufficient lateral extent and focusing the measurement in the central region it may reasonably be assumed that a one dimensional pattern of heat flow is present and the effects due to the presence of non-uniform conditions at the sample edges may be neglected. 


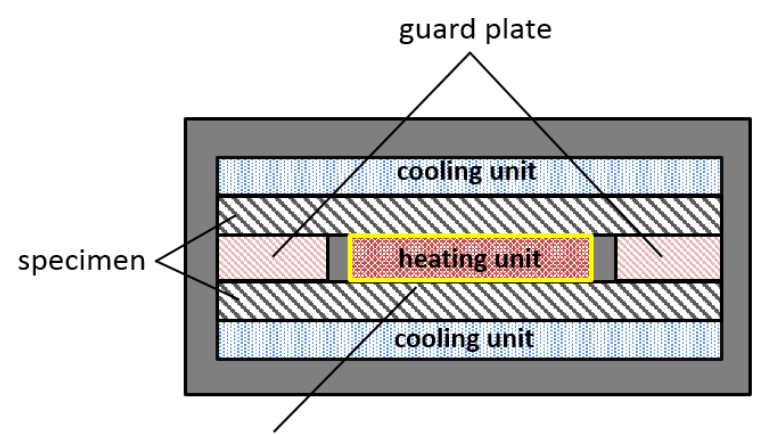

metering area (a)

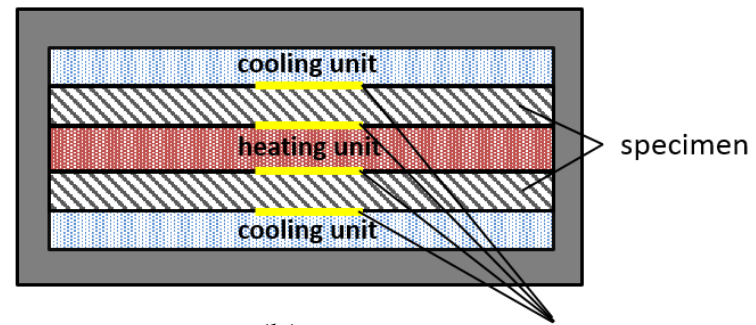

(b)

heat flow meter

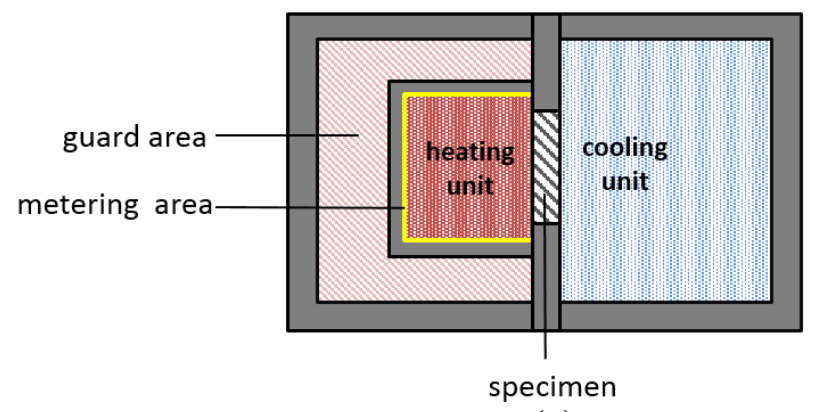

(c)

Figure 1: Steady-state thermal properties laboratory measurement method (a) hot-plate method, (b) flow meter method and (c) hot-box method

The hot-plate and flow meter methods are suited for characterising homogeneous materials, such as single glazing, insulation materials, etc. Goetzberger [34], Platzer [35, 36] and Suehrcke et al. [37] used hot-plate methods to measure the thermal characteristics of various Transparent Insulation Materials (TIMs). When faced with the issue of measuring the overall heat transfer through large, inhomogeneous structures, such as glazing with frames or shading devices, the hot-box method $[21,23,26,27,33]$ is better suited and more widely used [38]. In this apparatus (Figure 1 (c)), the specimen is mounted between two chambers that are kept at stable hot and cold conditions. The hot chamber serves as a guard to a metering box, which is mounted over the test sample. By maintaining equal temperatures in the hot chamber and the metering box, all the heat supplied to the metering box is assumed to be transmitted through the sample, which is then be used to determine the thermal transmittance of the sample [39]. Asdrubali and Baldinelli [40] compared three hot-box methods according to ISO 8990 [23], ASTM C1363 [26] and GOST 26602.1 [33] respectively. The results revealed that ISO 8990 and ASTM C1363 are very similar since they only measured the total heat transfer through the specimen; while GOST 26602.1 measured individual thermal characteristics of each component of the specimen, giving more information on the weaknesses and strengths of these components.

The method to obtain the dynamic thermal properties of building components uses thermocouples and heat flux meters to measure both the temperature gradient between any 
two surfaces of a building component, as well as the heat transfer rate through them, on the site where they are situated $[22,28]$. There are, however, various factors that can significantly affect the accuracy of the measurements taken. These include the type and quantity of sensors used, component location, and extreme ambient conditions. There are also some challenges that cannot easily be controlled during a measurement, such as seasonal weather, wind speed and radiant energy from the sun, which can make measurements impractical [41, 42].

\subsection{Numerical investigation methods}

The numerical investigation of the thermal properties of window systems can be classified into two major groups: 1) one-dimensional calculation based on standard calculation methods and 2) two- or three-dimensional simulation using finite element or finite volume models.

\subsubsection{Standard calculation method}

Standards describing the centre-of-glazing thermal behaviour of window systems include International Standards ISO 10292 [43] and ISO 15099 [44] and European Standard EN 673 [45].

Under these standards, the centre-of-glazing U-value, which is the reciprocal of total thermal resistance consisting of the internal and external surface thermal resistances and the thermal resistance of the glazing unit, can be described by the following equation:

$$
U=\frac{1}{R_{t}}=\frac{1}{\frac{1}{h_{e}}+R+\frac{1}{h_{i}}}
$$

where, $h_{e}$ and $h_{i}$ are the external and internal heat transfer coefficients, respectively. For a vertical soda lime glass surface, the value of $h_{e}$ used in standard EN 673 [45] is $25 \mathrm{~W} / \mathrm{m}^{2} \mathrm{~K}$ and the value of $h_{i}$ is $7.7 \mathrm{~W} / \mathrm{m}^{2} \mathrm{~K}$. These two values are standardised for the purposes of comparing glazing U-values. The total thermal resistance of the glazing unit, $R$, can be described for double glazing using the following equation [45]:

$$
R=\frac{1}{h_{r}+h_{g}}+2 \frac{d}{k_{p}}
$$

where $d$ is the thickness of each glass pane, $k_{p}$ is the thermal conductivity of each glass pane (W/mK); and $h_{r}$ and $h_{g}$ are the radiation conductance between two glass panes and the thermal conductance of air cavity, respectively. 
According to the empirical equation provided in EN673 [44], the radiation conductance, $h_{r}$, is given by:

$$
h_{r}=4 \sigma\left(\frac{1}{\varepsilon_{1}}+\frac{1}{\varepsilon_{2}}-1\right)^{-1} T_{m}^{3}
$$

where $\sigma$ is the Stefan-Boltzmann's constant, $T_{m}$ is the mean absolute temperature of the gas space, $\varepsilon_{1}$ and $\varepsilon_{2}$ are the corrected emissivities of the surfaces bounding the enclosed space between the panes at temperature, $T_{m}$. For uncoated soda lime glass surfaces, 0.83 can be used as the corrected emissivity [45], while the corrected emissivity for a glass surface with low-emissivity coating can be as low as 0.013 [46].

The thermal conductance of the gas in the cavity is given by:

$$
h_{g}=N u \frac{k_{g}}{s}
$$

where $s$ is the thickness of the air cavity, $\mathrm{kg}$ is the thermal conductivity of the air space. The Nusselt number, $\mathrm{Nu}$, which indicates the intensity of convection by representing the ratio between the pure conduction resistances to a convection resistance [32], is given by:

$$
N u=\text { Const. }(G r \cdot P r)^{e}
$$

where Const. is a constant and e is an exponent that makes it possible to account for the orientation of the glazing. For vertical glazing, these are 0.035 and 0.38 respectively [44]. The Grashof number, $G r$, and the Prandtl number, $P r$, are given by:

$$
G r=\frac{g \beta \Delta T s^{3}}{v^{2}}
$$

and

$$
\operatorname{Pr}=\frac{c_{p} \mu}{k_{g}}
$$

When calculating the U-value for the whole window component, including window frames and/or shading devices, International Standards ISO 15099 [44], European Standards EN 10077-1 [47] and EN 10077-2 [48], American Standards NFRC 100-2010 [49], and ASHRAE Standard [50] provide detailed guidance. Blanusa et al. [51] compared the differences between the ASHRAE calculation method and the ISO 15099 method, emphasising that small differences (i.e. 3\% or less) exist between the calculated thermal transmittance values they produce. 


\subsubsection{Numerical models}

Apart from experimental measurement and standard equation calculation methods, finite element or finite volume simulations are the most common approach used in order to obtain the thermal properties of window systems, especially when the air flow pattern in the cavity is of particular interest.

Computational Fluid Dynamics (CFD) tools have been used by researchers to solve the heat transfer problem and explore the air flow pattern in the vertical air cavity of both conventional double glazed units [52-56] and complex window systems [7, 57-61] . Zhao et al.[52] Wright et al. [54] and Ganguli et al. [55, 56] used a finite volume method to study natural convection in the cavity of double glazed units. The possibility of reducing free convection by integrating shading devices, such as horizontal Venetian blinds, pleated blinds and different configurations of fins into the cavity of double glazed units has also been investigated [7, 5761]. In their finite volume models, the following assumptions were made: 1) the glass surfaces facing into the cavity were set as two isothermal walls each with a different temperature to represent the temperature difference between indoor and outdoor environments; 2) the top and bottom surfaces bounding the cavity were assumed to be adiabatic; 3) the cavity was filled with air with a Prandtl number of approximately 0.71 [5761]. All thermophysical properties of the fluid were assumed to be constant, except for the fluid density and viscosity [57-61] .

The governing equations for these finite volume models are [57-61]:

Mass balance:

$$
\frac{\partial u}{\partial \mathrm{x}}+\frac{\partial v}{\partial y}=0
$$

Momentum balance:

$$
\rho\left(\mathrm{u} \frac{\partial u}{\partial x}+\mathrm{v} \frac{\partial u}{\partial y}\right)=-\frac{\partial \mathrm{p}}{\partial \mathrm{x}}+\mu\left(\frac{\partial^{2} u}{\partial x^{2}}+\frac{\partial^{2} u}{\partial y^{2}}\right)
$$




$$
\rho\left(\mathrm{u} \frac{\partial \mathrm{v}}{\partial \mathrm{x}}+\mathrm{v} \frac{\partial v}{\partial y}\right)=-\frac{\partial \mathrm{p}}{\partial \mathrm{x}}+\mu\left(\frac{\partial^{2} v}{\partial x^{2}}+\frac{\partial^{2} v}{\partial y^{2}}\right)+\rho g \beta\left(T-T_{C}\right)
$$

Energy balance:

$$
\rho c_{p}\left(u \frac{\partial T}{\partial x}+v \frac{\partial T}{\partial y}\right)=k\left(\frac{\partial^{2} T}{\partial x^{2}}+\frac{\partial^{2} T}{\partial y^{2}}\right)\left(+S_{h}\right)
$$

However, in most of these studies, long-wave radiation heat transfer, which accounts for two thirds of the total heat transfer across the air cavity [53], is neglected in the numerical modelling, which means the radiative heat transfer, $S_{h}$ in Equation (11), was not included. Some improved simulation methods have been implemented by Avedissian and Naylor [58] and Sun et al. [61], who used a "surface-to-surface" (S2S) model to include radiation. All the surfaces were assumed to be grey bodies, diffuse and opaque to thermal radiation. The air in the cavity was assumed to be a non-participating medium. The view factors $\left(F_{k j}\right)$, which depend on surfaces' size, separation distance and orientation, were computed before simulating the radiation. The S2S method can be represented by the following equation:

$$
J_{k}=\varepsilon_{k} \sigma T_{k}^{4}+\left(1-\varepsilon_{k}\right) \sum_{j=1}^{N} F_{k j} J_{j}
$$

Through CFD simulation, the convective heat flux and combined convective and radiative heat flux at the boundaries of the two glazing panes can be obtained from the converged temperature field. The overall thermal conductance $(h)$ including both radiation conductance between two glass panes and the thermal conductance of air cavity of a double glazing unit with or without a complex interstitial structure can be expressed in Equation (13):

$$
h=\frac{\left(\frac{\partial T}{\partial x}\right)_{p} k_{a}}{\Delta T}=\frac{q}{\Delta T}
$$

where $\left(\frac{\partial T}{\partial x}\right)_{p}$ is the air temperature gradient on the glazing pane's surface and $q\left(\mathrm{~W} / \mathrm{m}^{2}\right)$ is the average heat flux of combined convective and radiative heat transfer across the two surfaces. In this expression $\Delta T(K)$ is the temperature difference between the hot and cold isothermal surfaces. 
The Nusselt number of convective heat flux, which is determined by empirical equation in standard calculation method, can also be expressed by the calculated air temperature gradient using Equation (14):

$$
N u=\frac{\left(\frac{\partial T}{\partial x}\right)_{p} s}{\Delta T}=\frac{q^{\prime} s}{k_{a} \Delta T}
$$

where $q^{\prime}\left(\mathrm{W} / \mathrm{m}^{2}\right)$ is the average convective heat flux across the two surfaces.

Some of these models have been validated by temperature field visualisation obtained by interferometry [62-64], while other models have been validated by hot-box tests [65].

\section{Optical investigations of complex window systems}

There are two primary ways of expressing the optical properties of a window system containing a complex structure (e.g. interstitial shading devices) as illustrated in Figure 2. The first quantifies the strength and direction of the direct flux and then quantifies the remaining flux as a single value by assuming it is diffuse and contains no useful directional information. These data, describing the total amount of transmitted/reflected flux, are sufficient for predicting solar gains in cases where directional information is not important. The second is to use a method such as Bidirectional Scattering Distribution Functions (BSDF), which represent magnitude and the directional qualities of reflected or transmitted flux.

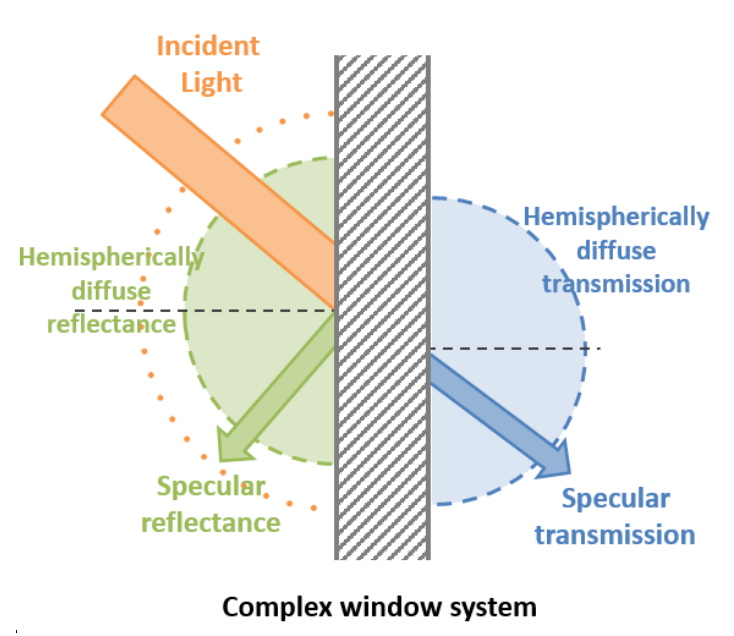

(a)

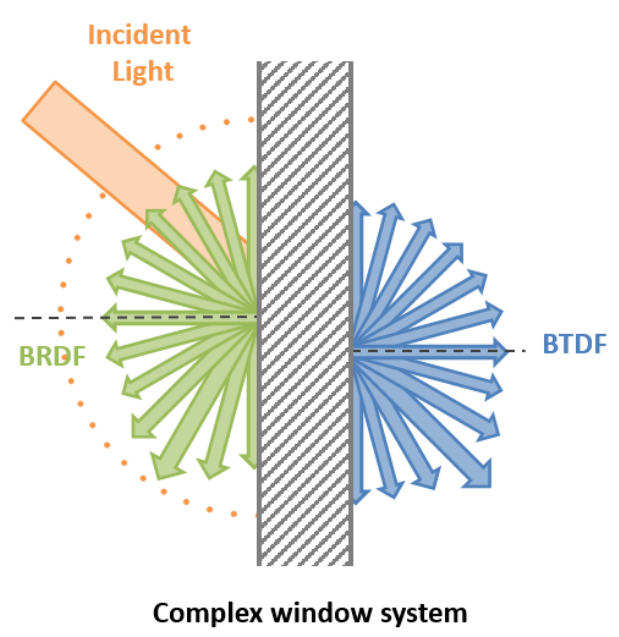

(b)

Figure 2: Methods for qualifying the transmission/reflection behaviour of glazing systems: (a) Simple: diffuse component expressed as an angular coverage value; (b) Complex: specular and diffuse components discretised and expressed as vectors. 
If there is a requirement to retain information relating to the direction of entry of the light to its direction(s) of exit, as the case of daylight distribution calculations, these more sophisticated measure measures of glazing behaviour are required.

The following two sections introduce experimental methods (i.e. spectrophotometer combined with integrating sphere measurements or goniophotometer measurements) and numerical methods (i.e. radiosity or ray-tracing) to obtain these two types of measure.

\subsection{Simple methods to measure total transmittance or reflectance}

The measurement of transmittance and reflectance of a building component can be obtained using a spectrophotometer and an integrating sphere. International Standard ISO 9050 [66] and European Standard EN410 [67] describe the methods used to calculate light and solar transmittance/reflectance based on the measured spectral transmittance/reflectance data. The technical requirements of the measurement apparatus and details of their use to determine these quantities are described in International Commission on Illumination (CIE) standard [68]. A schematic of the experimental setup is shown in Figure 3 [69].

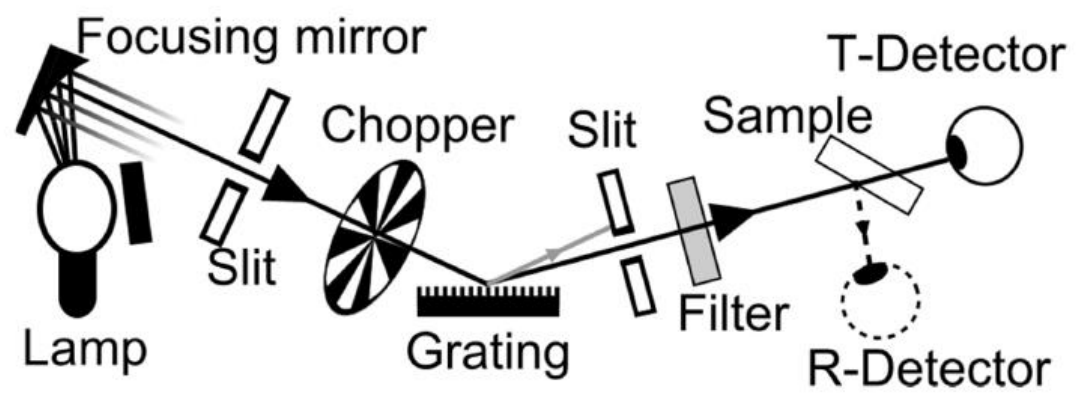

(a)
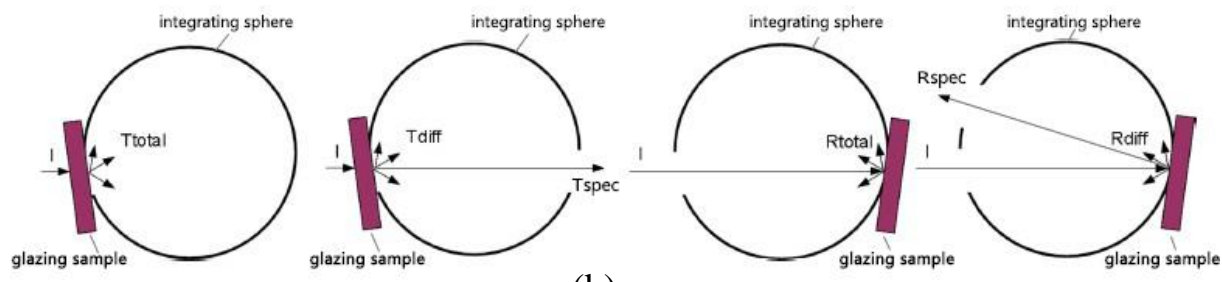

(b)

Figure 3: Experiment set up for measuring transmittance and reflectance (adopted from [69]): (a) overview of apparatuses; (b) use of integrating sphere/ spectrometer to qualify transmitted (T) and reflected $(R)$ components.

As shown in Figure 3 (b), the integrating sphere is used to detect the diffuse and the total magnitude of transmittance, $T_{\text {diff }}$ and $T_{\text {total }}$ respectively [69]. The diffuse transmittance is obtained by opening a port and letting the specular component exit the integrator. The 
specular transmitted component, $T_{\text {spec }}$ is determined from the difference, $T_{\text {total }}-T_{\text {diff }} \quad$ [69]. The same approaches are adopted in determining reflected qualities.

Photometric data can be obtained based on the measurement of light transmittance over a number of wavelength intervals in the visible wavelength range $(380 \sim 780 \mathrm{~nm})$. From these, the overall light transmittance, $\tau_{v}$, of a glazing component can be calculated using the following equation [67]:

$$
\tau_{v}=\frac{\sum_{380}^{780} D_{\lambda} \tau(\lambda) V(\lambda) \Delta \lambda}{\sum_{380}^{780} D_{\lambda} V(\lambda) \Delta \lambda}
$$

where $D_{\lambda}$ is the relative spectral distribution of light source (e.g. illuminant D65); $\tau(\lambda)$ is the spectral transmittance of the glazing over wavelength interval $\Delta \lambda$, and $V(\lambda)$ is the spectral luminous efficiency for photonic vision defining the standard observer. The solar transmittance is obtained by neglecting the $V(\lambda)$ correction and is typically determined over the wavelength range from $300 \mathrm{~nm}$ to $2500 \mathrm{~nm}$ [67].

A singnificant volume of research refers to this methodology in relation to the exploration of innovative glazing materials and window systems in terms of their respective optical prefromance [70-77]. However, this method of combining a spectrophotometer with an integrating sphere is mainly suited to the characterisation of homogenous glazing systems or materials. In the case of a window system that includes a complex interstitial structure, the standard integrating sphere measurement method can prove inappropriate as it does not easily accommodate the effects of anisotropy and spatial variation that are typically present. These can result in significant deviation in the directional characteristics of transmitted and reflected flux as well as variation in the total amount of flux transmitted/reflected. Not only can this give rise to significant errors in the estimates of transmission, these simple methods of measurement do not capture valuable directional information that is necessary to make accurate predictions of daylight distribution in the room served by these glazing systems.

\subsection{Numerical methods for predicting total transmittance or reflectance}

Radiosity methods are commonly used to calculate transmittance or reflectance for these complex fenestration systems, based on knowledge of the measured optical characteristics of each of the individual system component. This method is described in International Standard ISO 15099 [44]. Using a Venetian blind as an example, in the radiosity method, each slat is assumed to be divided into small patches, as shown in Figure 4 (a). Each 
patch is considered as a Lambertian reflector [78] and the view factors between all patches are paired in an iterative calculation [79]. When the beam radiation passes through the structure without intercepting any of the slats (Figure 4 (b)), it is regarded as contributing to the direct transmittance, $\tau_{\text {dir }}$, dir. When either the beam radiation or incident diffuse radiation intercepts the slats, it is regarded as contributing to the spatially averaged diffuse transmittance or reflectance, which may be broken down into sub components i.e. direct-todiffuse $\left(\tau_{\text {dir, dif }}, \rho_{\text {dir, dif }}\right)$ and diffuse-to-diffuse $\left(\tau_{\text {dif, dif }}, \rho_{\text {dif }, \text { dif }}\right)$ as shown in Figure 3 (c, d) [44].

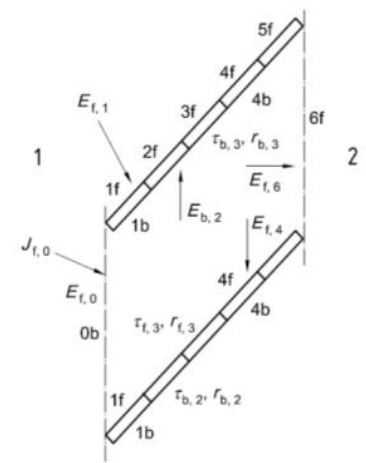

(a)

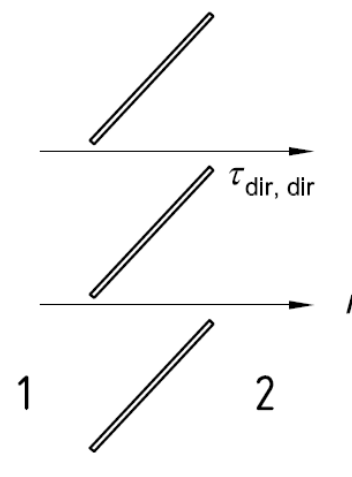

(b)

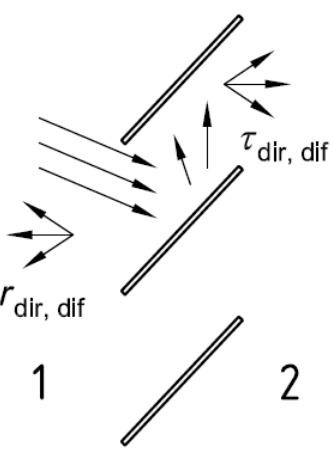

(c)

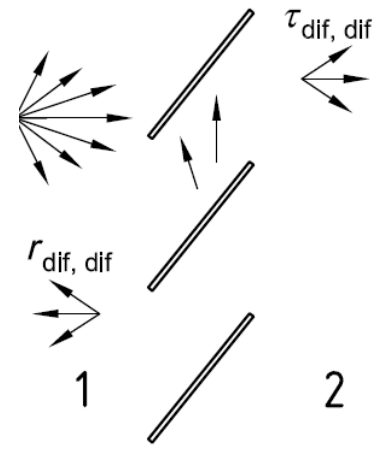

(d)

Figure 4: (a) discretisation used to model a Venetian blind, (b) the direct-direct transmittance of the shading device, (c) the direct-diffuse transmittance and reflectance of the shading device and (d) illustration of the diffuse-diffuse transmittance and reflectance of the shading device [44]

The radiosity method as described in ISO15099 has been utilised in building simulation software, such as EnergyPlus, to calculate the transmittance and reflectance of a window system with complex interstitial structures [79]. Its application to window systems with integrated Venetian blinds has been implemented by a number of investigators [80-88] and has proved to be a quick and effective numerical method. The assumption of Lambertian surfaces means that this method is not suitable for systems with highly specular surfaces, however, overcome this limitation, researchers [89-91] have proposed a mixed method that combines radiosity with a ray-tracing method to yield both the specular and scattering optical characteristics.

This approach can yield simple averaged optical properties, however, when the application requires the outgoing directions of light to predict its distribution in a space, knowledge of only the ratio between the amounts of transmitted or reflected light to the 
amount of incident light is no longer sufficient. A detailed knowledge of directional optical properties is necessary.

\subsection{Complex methods for determining transmittance and reflectance - the Bidirectional Scattering Distribution Function (BSDF)}

The Bidirectional Scattering Distribution Function (BSDF) comprises matrices of coefficients that for light from each incident direction quantify the proportion transmitted in each outgoing direction. It is currently regarded as the most important method for characterising complex glazing systems, allowing them to be represented with precision in daylight analysis simulations. The BSDF can be further divided into a Bidirectional Transmittance Distribution Function (BTDF) and a Bidirectional Reflectance Distribution Function (BRDF). The BSDF based on Klems' angle basis (Figure 5 (a) ) [92, 93] is the most commonly used format. It is formed by 145 x 145 matrices including both solar and optical spectrum. Each matrix describes reflectance or transmittance distribution in the outgoing hemisphere for a single incidence angle from the incoming hemisphere. Equation (9) [94] illustrates how the value of total transmitted radiation is obtained with regard to any particular angle of incidence (azimuth, $\theta_{1}$ and altitude, $\varphi_{1}$ ). This value is derived using a matrix calculation based on the result of the sum of the individual products of the luminous coefficients and incident irradiance, for each segment of the hemispherical basis.

$$
\tau\left(\theta_{1}, \varphi_{1}\right)=\sum_{\mathrm{k}=1}^{145} \operatorname{BTDF}\left(\text { patch }_{\mathrm{k}}\right) \int_{0}^{2 \pi} \mathrm{d} \varphi_{2} \int_{0}^{\pi / 2} \cos \theta_{2} \sin \theta_{2} \mathrm{~d} \theta_{2}
$$

where, $\theta$ and $\varphi$ define the boundaries of each patch as shown in Figure 5(b).

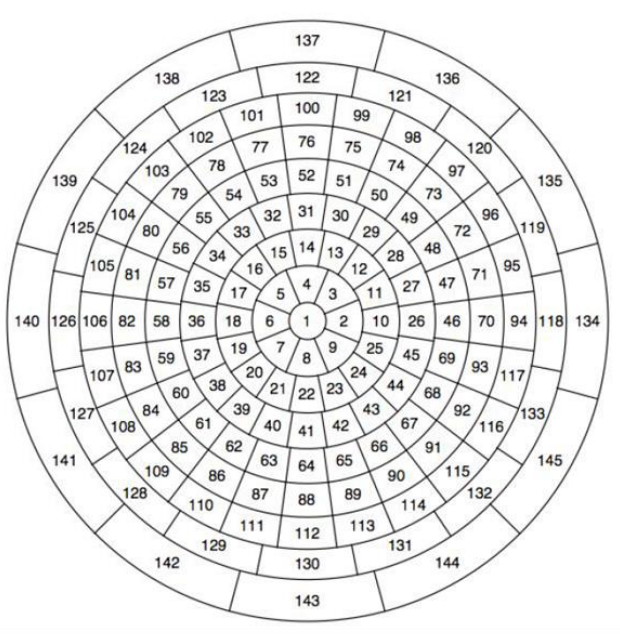

(a)

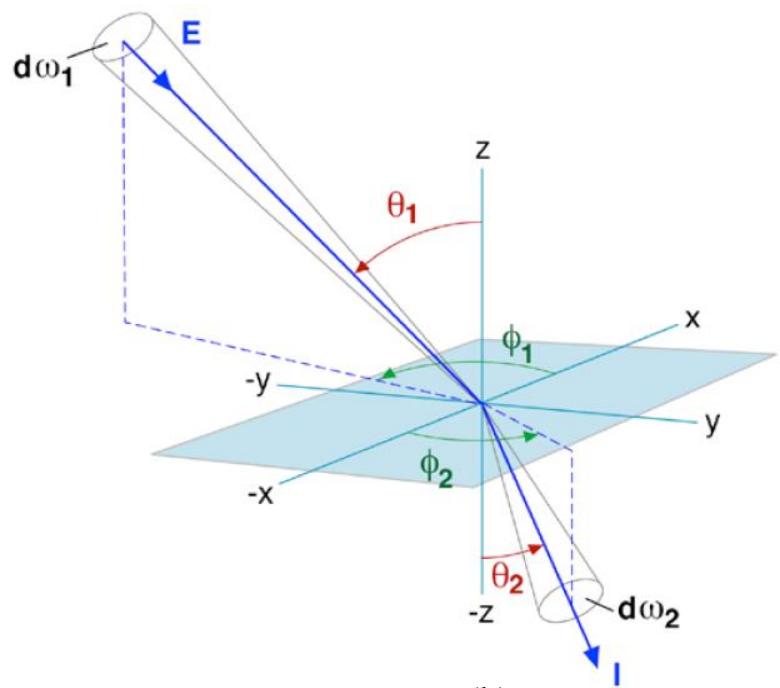

(b) 
Figure 5: (a) Klems' 145-patch hemispherical basis with numbered subdivisions; (b) coordinate system for bidirectional measurements [94]

Recent investigators have focused on the development of measurement techniques for complex window systems in an attempt to capture the respective BRDF and BTDF data. The instrument most commonly used is a goniophotometer and these can be divided into two catalogues: 1) scanning-based instruments, where each outgoing direction of light is detected by each individual movement of the detector, and 2) video-based instruments, where digital imaging techniques are used to collect the outgoing direction of light from a single image. The schematic diagrams and features of goniophotometers are illustrated in Table 1.

As suggested by the name, the scanning-based method measures all required incoming and outgoing light flux directions by moving the sample, detector or light source. Each value in the BSDF matrix is measured discretely. Although, this method is intuitive and can offer high and variable angle resolution [69], it is an onerous time consuming task (i.e. 4 to 30 days according to [95]). Moreover, the scanning of discrete BSDF-related data presents the potential risk of omitting significant features that may lie between the points where measurement are taken $[69,95]$.

The principle of the video-based method is to use a CCD camera quipped with a fisheye lens to collect the light emerging after being reflected or transmitted from the test sample under investigation. By using the camera, only one image is needed to investigate the whole light distribution for any given angle of incidence. Thus, the period of time required for the measurement can be dramatically reduced [96]. This method normally requires a period of time somewhere between a few hours to only several minutes to generate the BRDF/BTDF resulting from the hundreds of possible incidence angles [95]. This method was developed by Ward [97] at LBNL in 1992 for the purpose of modelling and photo-realistic rendering of lighting in interior spaces. It was carried forward by Andersen [95, 96, 98-100] in EPFL. The EPFL device differs from others as the hemispherical receiving screen has been replaced by an approximation to a sphere comprising six triangular diffusing projection screens. The luminance on each pixel recorded over these triangular screens is measured and used to covert to the BSDF data from the images taken by the CCD camera, as shown in Tables 2 and 3. 
Table 2: Goniophtotometers to measure the BSDF data

\begin{tabular}{|c|c|c|c|c|}
\hline Institute & LBNL, USA & ISE, Germany & Cardiff University, UK & pab Ltd, Germany \\
\hline Schematic & & & & \\
\hline Method & Scanning-based & Scanning-based & Scanning-based & Scanning-based \\
\hline Year & 1988 & 1994 & 2001 & 2006 \\
\hline BTDF & $v$ & $\mathrm{v}$ & $\mathrm{v}$ & v \\
\hline BRDF & - & $v$ & - & $v$ \\
\hline $\begin{array}{l}\text { Spectral } \\
\text { capability }\end{array}$ & - & - & $v$ & - \\
\hline $\begin{array}{l}\text { Validated } \\
\text { by }\end{array}$ & measured g-value & $\begin{array}{l}\text { transmittance measured with integrating } \\
\text { sphere }\end{array}$ & $\begin{array}{c}\text { measured g-value, transmittance measured with } \\
\text { integrating sphere }\end{array}$ & - \\
\hline Ref. & [101-104] & [105] & [106] & [107] \\
\hline
\end{tabular}


Table 3: Goniophtotometers to measure the BSDF data (continued)

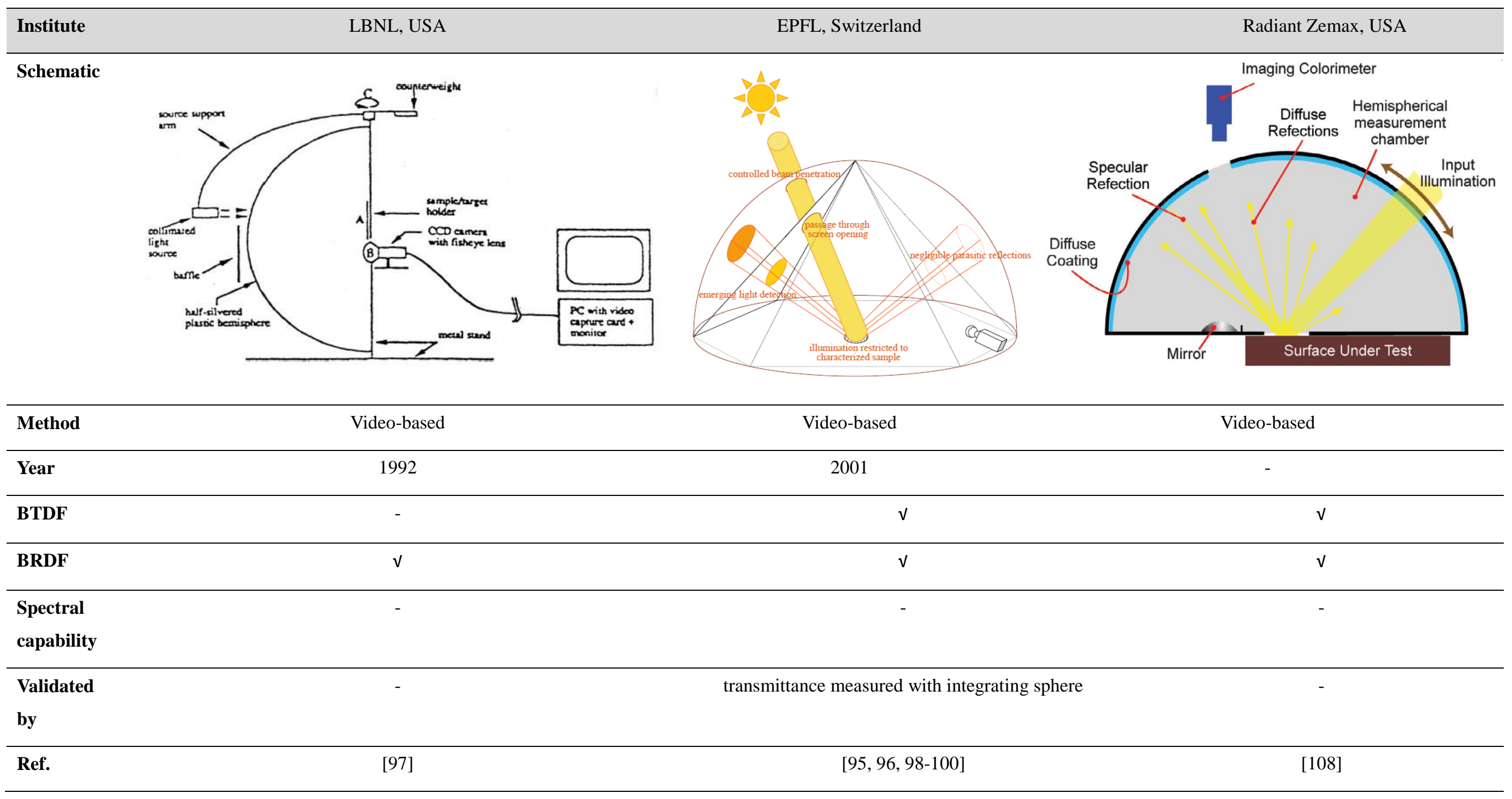


The complexity and the levels of skill required to operate goniophotometers means that they have received relatively low levels of uptake in both academic and commercial sectors.

As an alternative, researchers have been developing and validating virtual goniophotometers based on commercial forward ray-tracing simulation tools and using these in conjunction with virtual representations of complex fenestration systems (based on description of their geometry and optical characteristics) to obtain BSDF data. This approach is easier to implement, less expensive, less time-intense and more flexible for conducting parametric studies. Researchers in LESO-PB/EPFL [98, 99] used commercial ray-tracing software TracePro to model a virtual goniphotometer, which has same configuration (i.e. receiving surfaces that consist of six triangles) as the experimental goniophotometer in EPFL, as shown in Figure 6 (a). The results were validated by comparison with experimental data and showed a difference of between $2 \sim 14 \%$. Another numerical goniophotometer was developed by de Boer [109] using the ray-tracing tool OptiCad, as shown in Figure 6 (b). This method used virtual sensors to receive flux on individual geometric positions and then calculated the BSDF values. The resolution of this numerical goniophotmeter can be defined by the user [95].

Recently, a free, open-source ray-tracing method- genBSDF implemented in RADIANCE-[110] was proposed and validated by comparing the predicted BSDFs with results obtained using other methods (i.e. TracePro simulation and real goniophotometer measurements) [111]. The results obtained from genBSDF are stored in an XML file, which can be used directly in lighting simulation tools such as RADIANCE, to determine daylighting performance of window components. By imputing data into Window 6 and then using energy simulation tools such as EnergyPlus, it is possible to predict the energy performance when applying these window systems to a building [112]. Sun et al. [112] used genBSDF to predict the optical characteristics of a window system with integrated Transparent Insulation Material and then used the obtained BSDF data in an annual daylight simulation to generate a picture of daylight performance when applying this novel window system in a small room. 


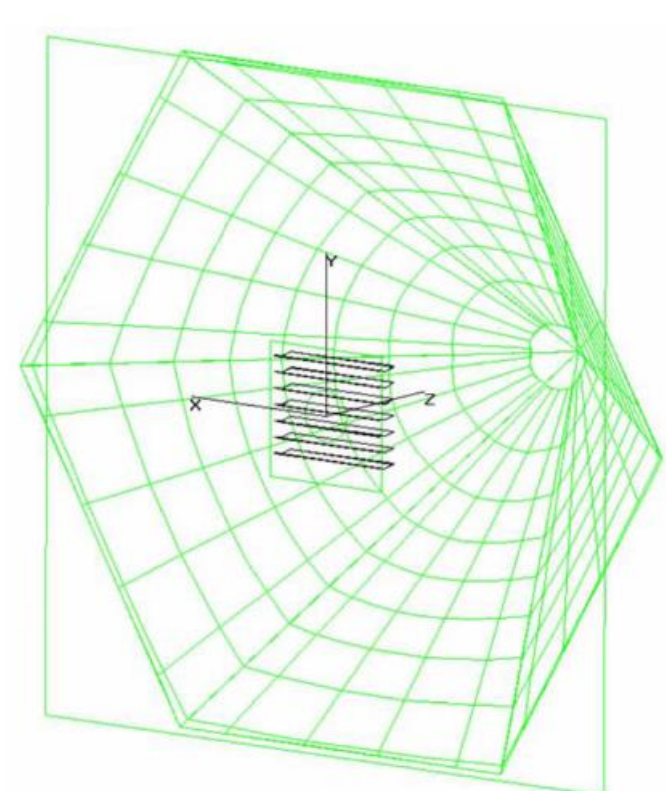

(a)

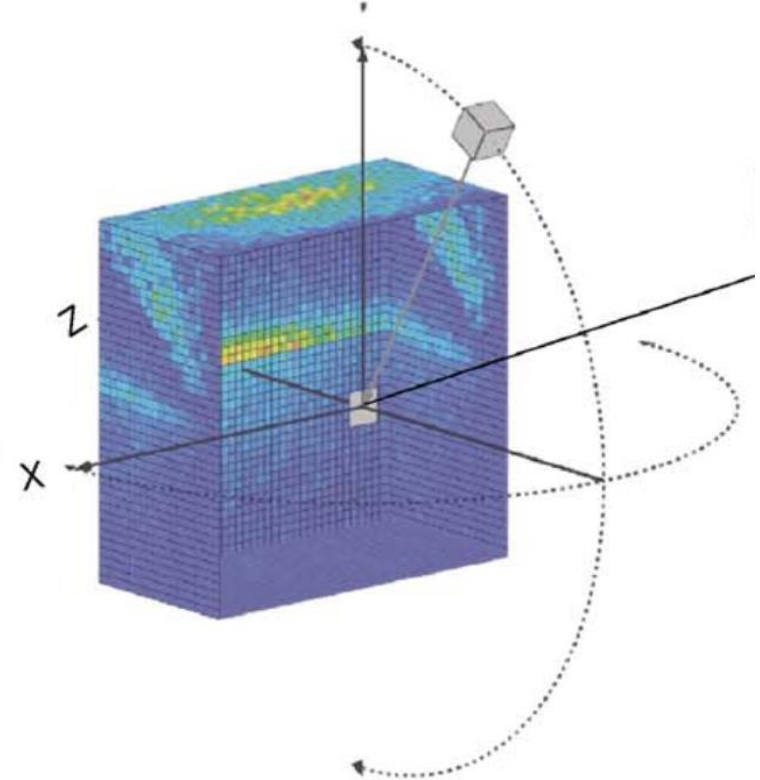

(b)

Figure 6: Virtual goniophotometers generated using (a)TracePro [98] and (b)OptiCad [109] 


\section{Daylight performance predictions for buildings with complex fenestration systems}

The quantity, quality and distribution of natural daylight passing through window systems and illumination of an interior space, play an important role in determining building energy efficiency and indoor environmental quality [113]. For example, excess sunlight in summer results in unwanted glare and presents an overheating risk, insufficient daylight results higher electricity consumption due to the use of artificial lighting, etc. Additionally, appropriate provision of daylight is also proven to have beneficial effects on human health, mood, activity and working efficiency [114].

Traditional approaches to evaluating the quantity, quality and distribution of daylight, which are in the main based on the use of rules of thumb or simplified calculation methods, such as daylight factor (DF), are increasingly becoming perceived as inadequate [114]. Key concerna are that they offer only an average picture of what is in reality a time varying behaviour, and that they neglect the contribution made by sunlight and focus only on the illumination produced by skylight. A number of new and refined metrics, such as Useful Daylight Illuminance (UDI) and Daylight Glare Probability (DGP), have been proposed [115-117] as a means of improving the objectivity and accuracy of studies evaluating the effectiveness of daylighting strategies and designs. These more sophisticated metrics are made possible through the use of dynamic simulation tools (e.g. RADIANCE [100, 118-120], Daysim [121-127], etc.). In this section, the daylight assessment metrics, from basic metrics and their limitations to more advanced metrics and their advantages, are introduced and analysed. The daylight evaluation tools, used in building services engineering and related research fields, are discussed and summarised.

\subsection{Daylight assessment metrics}

\subsubsection{Daylight availability}

Daylight availability describes the available daylight transmitted through a window system to an indoor space. It can be defined by static metrics, such as Daylight Factor (DF) or the illuminance or luminance in a space on specific days, or through dynamic/climatebased metrics, such as Daylight Autonomy (DA), Useful Daylight Illuminance (UDI) or Annual Light/Sunlight Exposure.

\subsubsection{Static metrics}




\section{- Daylight factor (DF)}

Daylight factor (DF) is the ratio of interior illuminance at a point within a building to the exterior horizontal illuminance under an unobstructed CIE overcast sky [128]. DF has found favour in building daylight assessment because it is a simple way to calculate daylight availability at a given location in buildings. It considers the worst case scenario, i.e. an "overcast sky", for daylight assessment and may be paired with representative values of illuminance for a given site to provide estimates of daylight autonomy. Various sources of design guidance and standards recommend DF values for different building types, e.g. British Standards for Lighting in Buildings [129], American IESNA Standards [130], Chinese Standards for Daylight Design of Buildings [131] etc. Typically these recommend a minimum DF of $2 \%$ for an office space. The thresholds of $2 \%$ and $5 \%$ can also be used to divide a space into three regions [132]: a perimeter region with DF of more than 5\%, where no artificial lighting is required; an intermediate region with DF between $2 \%$ and $5 \%$, where artificial lighting partially supplements daylight, and an inner region with DF less than $2 \%$ that relies on permanent artificial lighting.

However, because DF is a static metric it does not take account of a building's site, associated climate, or time of day [133]. Similarly, the assumptions that underlie the concept of DF mean that variable sky conditions, and in particular direct solar radiation, which has significant influence on the daylight performance, are not considered. Any one of these has the potential to result in considerable loss of accuracy if there is a need to predict realistic levels or patterns of daylight distribution [134]. While there are some standards that advise against over illumination from daylight (by suggesting optimum DFs) there is a general risk that the DF approach can be interpreted by designers as a metric that should be "maximised'. This may be achieved by enlarging opening sizes, increasing transmittance of glazing and improving reflectivity of ceiling and wall finishes. These approaches can lead to extreme luminous environments with oversupply of daylight and high glare risk, as well as a propensity for thermal discomfort with overheating in summer and under heating and/or high heating demand in winter [133].

\section{- Clear sky studies on solstice and equinox days}

Rendering of daylight in a space with a specific window system under clear sky conditions at 9 am, noon and $3 \mathrm{pm}$ on solstice and equinox days is able to provide an easily accessible impression of how daylight distribution changes for these key times of day/year. Figure 7 shows false colour contours in a room with three different window designs on 
solstice and equinox days under clear sky conditions [135]. It can be seen that the amended façade designs lead to more light being transferred into the depth of the room improving both the average daylight levels and distribution uniformity. LEED Version 3.0 requires a minimum light level of 269 lux (25 footcandles) on the equinox at 9 am and 3 pm under CIE clear sky conditions for an office building [136]. The clear sky studies combined with DF leads to a more balanced daylighting design as the high levels of illumination predicted by the former counter the temptation to over illuminate implicit in the latter. Both of these approaches represent climatic extremes and fail to exploit the opportunities to develop a picture of the luminous environment that reflects the time varying nature of the daylight resource. Alternative approaches that make use of climatic data specific to the site offer a means of achieving this. [133].

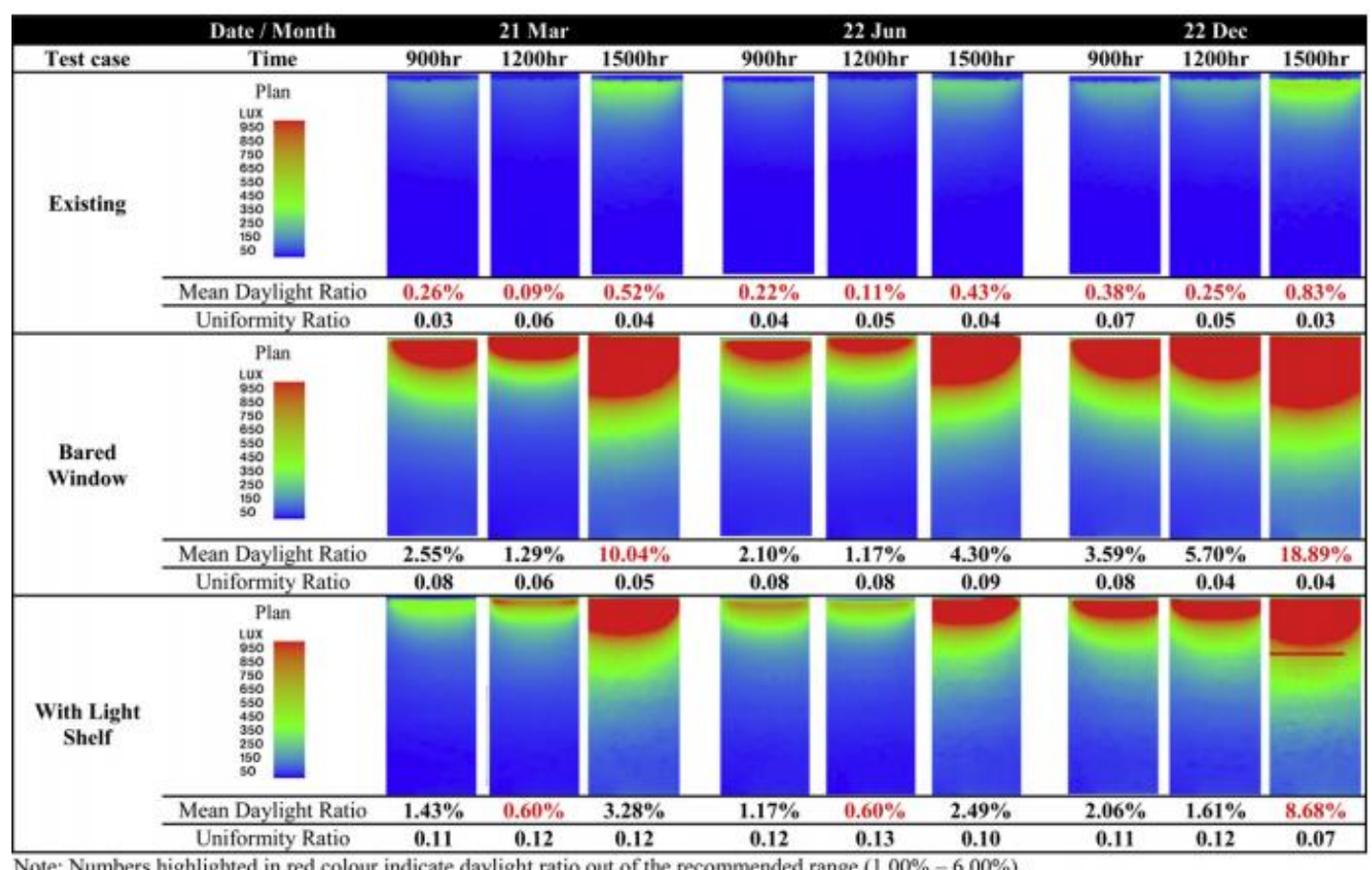

Figure 7: False colour contour in a room with three different window designs on solstice and equinox days under clear sky conditions (adopted from [135])

\subsubsection{Dynamic metrics}

The development of daylight simulation software provides the possibility of annual and dynamic simulation of indoor daylight performance and has seen the DF approach and the clear sky approaches being gradually replaced by more powerful and sophisticated metrics. Despite this, both the DF approach and clear sky studies remain useful and meaningful as a preliminary design metric [137] or as metrics complementary to an accurate dynamic daylighting assessment systems [117, 126, 138]. 
What these newer dynamic approaches offer is an alternative to simulating under a standard fixed condition or under a small number of scenarios, that instead makes use of a weather file with hourly measurements of solar irradiance. From these, they are able to return a comprehensive set of hourly simulation results for daylight performance providing a clearer picture of the luminous environment within a building over the course of a typical year.

\section{- Daylight autonomy (DA)}

Daylight autonomy ( $\mathrm{DA}_{\mathrm{x}}$ lux)is a climate-based metric defined as the percentage of occupied hours in a year when a minimum illuminance threshold ( $\mathrm{x}$ lux) can be met by daylight alone [139]. Illuminances of 300 lux $\left(\mathrm{DA}_{300} \mathrm{lux}\right)$ and $500 \mathrm{lux}\left(\mathrm{DA}_{500} \mathrm{lux}\right)$ are the most common target thresholds for offices, classrooms and libraries [133, 140]. For any given point in a building, daylight is considered sufficient if the daylight autonomy exceeds $50 \%$ of the occupied hours of the year (ie DA 300 lux or 500lux $>50 \%$ ) [140-142]. This concept is also used in defining spatial daylight autonomy (sDA) as described in IESNA LM [143], which is defined as the percentage of floor area achieving a given $\mathrm{DA}_{\mathrm{x}}$ lux [127]. According to the investigations by Reinhart et al. [140, 142], who compared occupants' subjective evaluations of daylight with simulated results for various daylight metrics (Figure 8), sDA was found to be the most reliable metric for predicting the perceived daylight condition within interior spaces.

A further modification of the daylight autonomy metric, continuous daylight autonomy (cDA or $\mathrm{DA}_{\mathrm{con}}$ ), defines these time steps in daylight period when the daylight illuminance lies below an illuminance threshold ( $\mathrm{x}$ lux), these time steps award partial credits (illuminance provided by daylight/ illuminance required space)[144]. In seeking to quantify over-illumination, maximum Daylight Autonomy (maxDA) is an extended metric based on DA that attempts to assess the possibility of glare [145]. In use, max DA, sets a threshold of ten times of the required illuminance as the maximum [145]. However, this factor of ten is based on intuition rather than being grounded in studies of visual comfort [144]. 


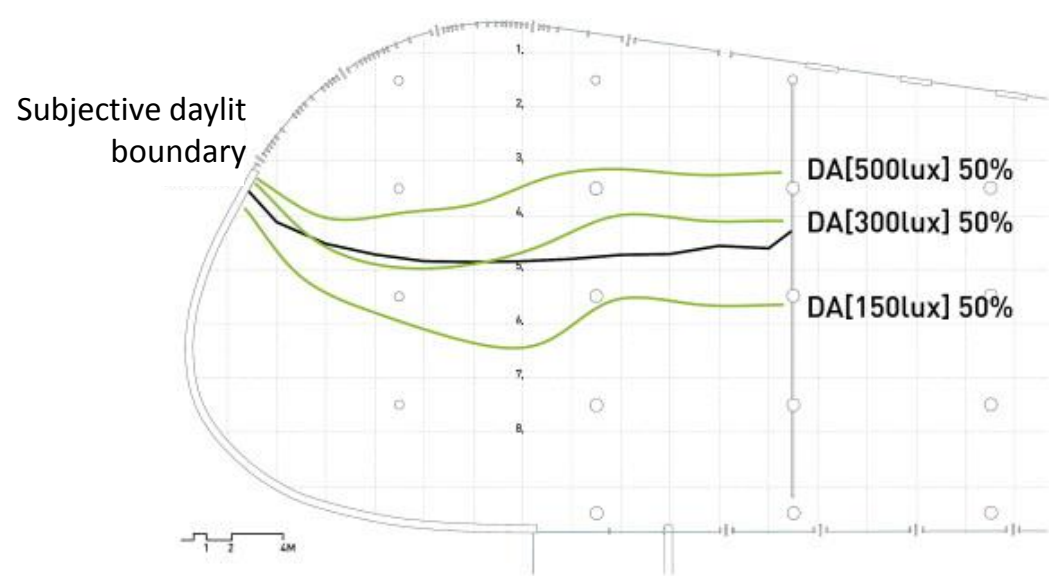

Figure 8: Comparison between $\mathrm{DA}_{150}$ lux $50 \%, \mathrm{DA}_{300}$ lux $50 \%, \mathrm{DA}_{500}$ lux $50 \%$ and daylit area boundary line from occupants' subjective evaluation [140]

\section{- Useful Daylight Illuminance (UDI)}

The DA metrics provide an indication of the percentage of daytime hours during which sufficient illuminance can be supplied by daylight alone. However, this value can be misleading because when there is an oversupply of daylight (e.g. illuminance value $>3000$ lux), building occupants tend to deploy blinds, shades or curtains to control visual and thermal discomfort [146]. Based on investigations of occupant response to varying daylight illumination, the Useful Daylight Illuminance (UDI) metric was proposed [117]. This places the results from hourly simulation into one of three bins where the central bin is defined by lower and upper useful illuminance thresholds.

Results landing in the lower bin (UDI $\mathrm{L}_{100 \mathrm{lux}}$ ) suggest periods when daylight alone is insufficient either as the sole source of illumination or to contribute significantly to offsetting use of artificial lighting. Results landing in the upper bin (UDI>2000lux) indicate periods when daylight is likely to lead to visual or/and thermal discomfort. Results falling into the intermediate bin (UDI $\left.{ }_{100-2000 l u x}\right)$ are considered to be useful, and can be further subdivided around a threshold of 500 lux. Values of UDI in the range of 100-500 lux land in what has been termed a "supplementary" bin, in which daylight is deemed sufficient as a sole source of illumination or making a significant contribution to illumination when used in conjunction with artificial lighting. Values of UDI in the range of 500-2000 lux land in what has been termed as "autonomous" bin, in which daylight is perceived either as desirable or at least tolerable $[112,117,147]$. Other values for the threshold between the intermediate and upper bin have been proposed e.g. 2500 lux [147] or 3000 lux [146], as have values for the threshold to subdivide the useful bin, e.g. 300 lux [146]. 
Overlaying plots of UDI on the floor plan of a building under investigation can provide an intuitive description of the available daylight distribution in a space [133] or allow quick comparisons between different designs of window system or glazed façade [117, 148]. As an example, Figure 9 illustrates results from a study of a façade designed with and without a light shelf at different window-to-wall ratios (WWR). From this it can be found that, with the presence of light shelf, the daylighting quality near the window was improved while there is a slight deterioration for the deeper ends of the room for all cases under different windowto-wall ratios [148].

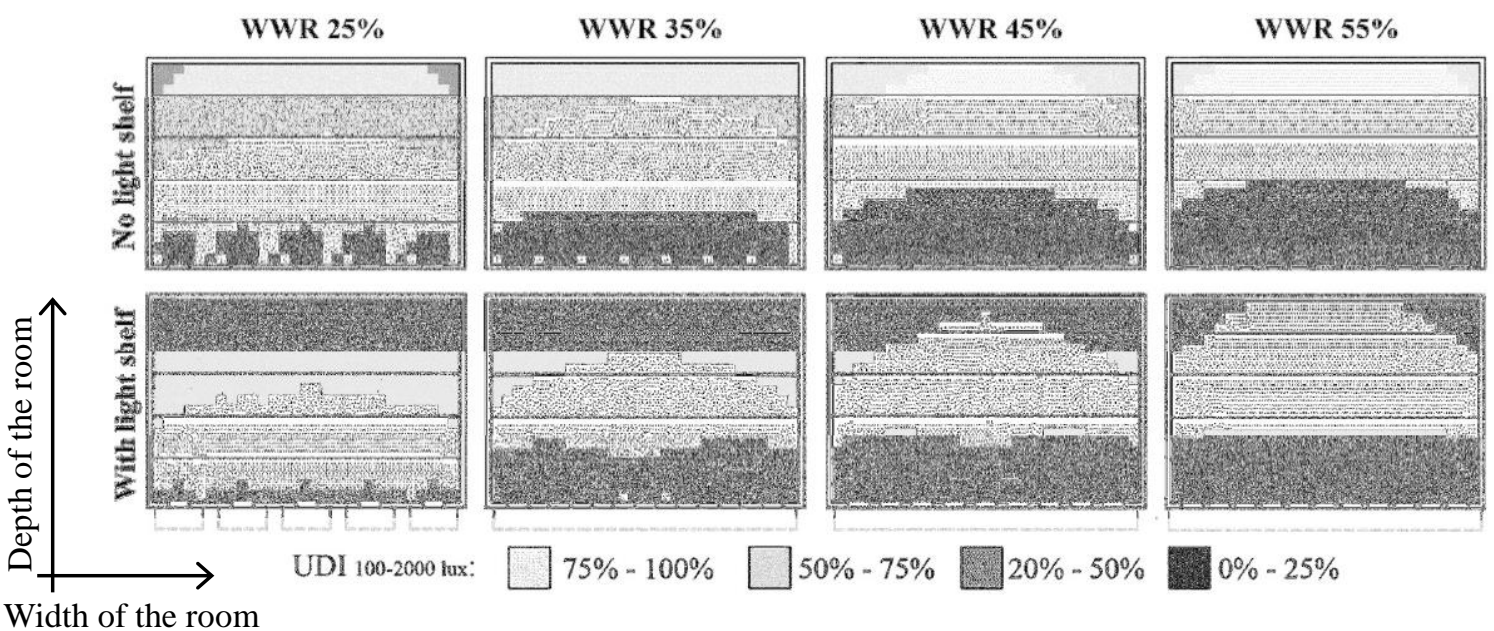

Figure 9: Comparison between UDI maps for façade with and without light shelf at different window-to-wall ratios (WWR) [148]

\section{- Annual Sunlight/Light Exposure (ASE or ALE)}

Annual Sunlight Exposure (ASE) or Annual Light Exposure (ALE) is a metric that cumulates the amount of light incident on a given point over the course of a year [133]. It is a well-established metric for assessing whether daylight levels are appropriate in spaces for artwork where the sunlight has a propensity to cause damage to exhibitions [149] or in spaces designed for plants to ensure sufficient sunlight for them to grow. In IES LM-83 [143], ASE is defined as the percentage of the given plane of interest within a space that has direct sunlight for more than 250 hours in a year.

\subsubsection{Visual comfort levels and daylight}

Once the requirement for achieving sufficient light for efficient visual performance through daylight design has been met, a second and equally important requirement is to 
ensure a comfortable and pleasing visual environment [150]. The metrics for quantifying these visual qualities include illuminance Uniformity Ratio (UR) and Glare related metrics.

\section{- Illuminance Uniformity Ratio (UR)}

Uniformity is the ratio between maximum and minimum illuminance on a defined plane inside a space $[112,151]$. As the natural light variations inside a room can result in sharp illuminance contrasts, and as human vision is more sensitive to this contrast than to the absolute amount light within a space, the uniformity becomes a very important metric. CIBSE [152] recommend uniformity should not exceed 1:5 for a naturally lit space and the BREEAM [153] assessment method specifies a daylight ratio between average illuminance of a given task area and its immediate surrounds of 1:2.5.

\section{- Glare}

Glare describes the condition where the luminance level within the field of vision exceeds the brightness to which eyes are adapted. It is a relatively subjective metric as it is dependent on the observer's personal preference, age, gender, etc. According to Reinhart [133], glare can be subdivided into disability glare and discomfort glare; the first describes the inability of a person to see a certain objects in a scene due to glare; while the latter describes the premature tiring of the eyes caused by glare. Disability glare is relatively easy to identify, however, discomfort glare, is more subtle and harder to quantify. Glare Index (GI) has been used as a metric for many years; however, early variants such as Unified Glare Rating (UGR) and Daylight Glare Index (DGI) are based on relatively small glare source typical of artificial lighting. In 2006, a discomfort daylight glare index named Daylight Glare Probability (DGP) was introduced and validated by Wienold and Christofferen [150]. The DGP has become the preferred metric for assessing glare within a daylit space.

DGP is expressed as follows [150]:

$$
\mathrm{DGP}=5.87 \times 10^{-5} \mathrm{E}_{\mathrm{v}}+9.18 \times 10^{-5} \log \left(1+\sum_{\mathrm{i}} \frac{\mathrm{L}_{\mathrm{s}, \mathrm{i}}^{2} \omega_{\mathrm{s}, \mathrm{i}}}{\mathrm{E}_{\mathrm{v}}^{1.87} \mathrm{P}_{\mathrm{i}}^{2}}\right)+0.16
$$

where $E_{v}(\mathrm{lux})$ is the vertical eye illuminance produced by the light source, $L_{s}\left(\mathrm{~cd} / \mathrm{m}^{2}\right)$ is the luminance of source; $\omega_{s}(\mathrm{sr})$ is the angular size of source seen by the observer; and $P$ is the position index, which expresses the change in experienced discomfort glare relative the angular displacement of the source from the observer's line of sight. The method can be 
generated by rendering a HDR image for a position in a daylit space for every daylight hour of the year, and then comparing the luminance ratios and adjacencies to determine an average probability that an observer at that point would find it objectionable.

Performing this calculation for even a simple space with one observer position over a period of a year imposes a significant computational overhead and can be highly time consuming, so in practice, a simpler method is desirable. Wienold $[115,116]$ proposed a simplified version of DGP, DGPs, where the logarithmic term quantifying the luminance and solid angle of the source seen from the observation point is neglected:

$$
\text { DGPs }=6.22 \times 10^{-5} \mathrm{E}_{\mathrm{v}}+0.184
$$

In use, the DGP thresholds of $0.35,0.40$ and 0.45 can be used to divide the DGP results calculated for occupied hours of a year into four bins: lower than 0.35 is 'imperceptible' glare sensation, between 0.35 and 0.40 is 'perceptible', between 0.40 and 0.45 is 'disturbing', while higher than 0.45 is deemed 'intolerable'. The visual quality of the space may then be rated according to the following scale: 'Best' class corresponds to over 95\% of office hours having imperceptible glare sensation, 'Good' class requires over 95\% of office hours having glare weaker than perceptible, while 'Reasonable' class will have over $95 \%$ of office hours with glare weaker than disturbing $[115,116,150]$. Implicit in these calculations is the assumption that the sun is not contained within the field of view, i.e. DGPs cannot be used to evaluate glare probability when the sunlight directly hits the observer [13].

\subsubsection{Lighting energy consumption}

Standard and complex windows typically form part of an integrated system where artificial lighting is used to complement a daylighting strategy and help ensure illuminance levels do not drop below design targets. Use of daylight simulation methods provides not only a more accurate assessment of the daylight/artificial lighting interaction and hence lighting energy demand, but also the ability to quantify how this impacts on a building's heating and cooling energy demands $[112,123,126,138,151]$. Figure 10 presents the result from a simulation that considers complex daylight availability metrics (DA, DGI and UR) and energy consumption, offering a holistic picture of performance in terms of indoor comfort level and energy efficiency for a particular building design [151]. 

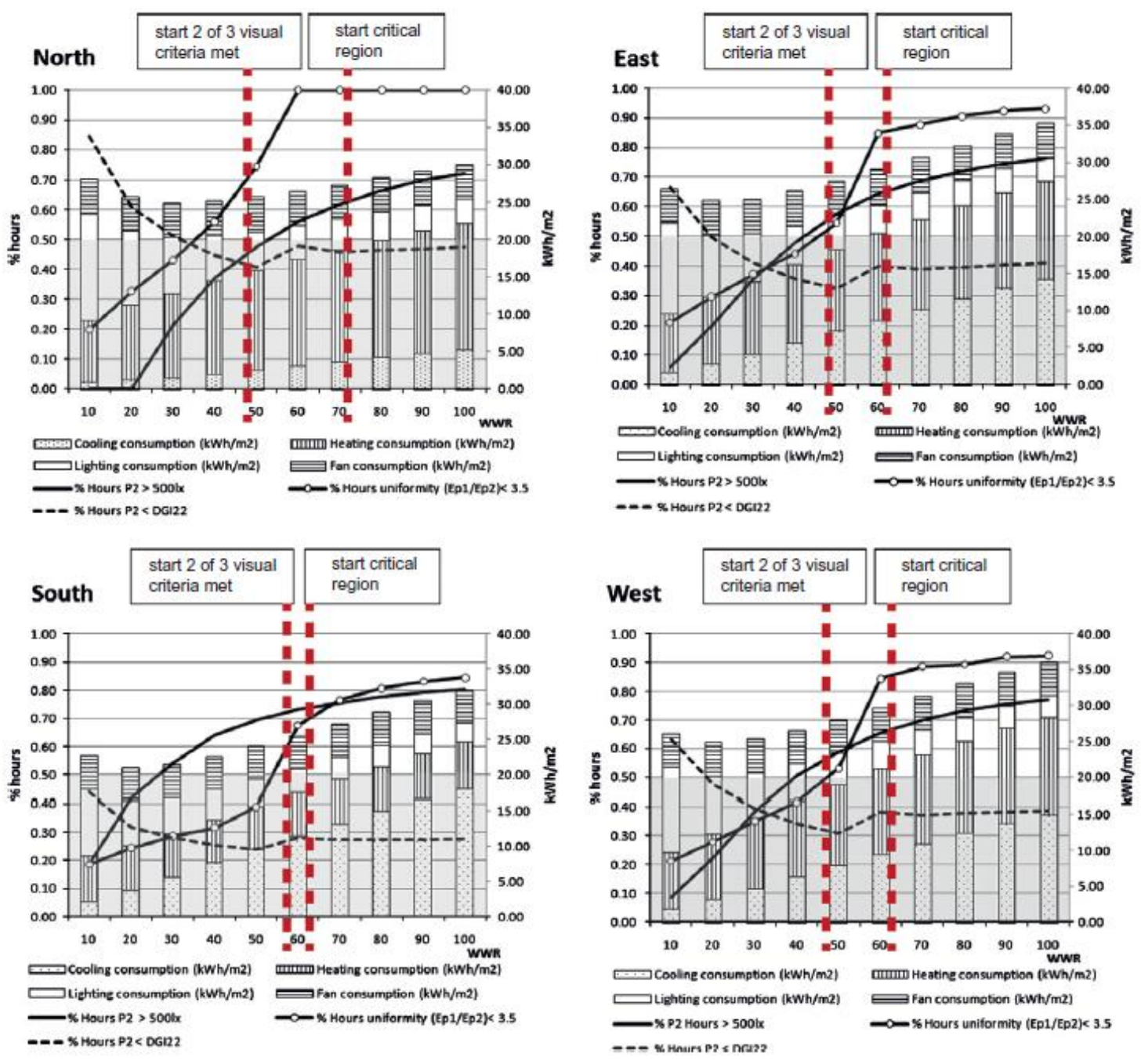

Figure 10: Overall consideration of uniformity, DA, DGI and energy saving for building design with different window-to-wall ratio (WWR) [151]

\subsection{Daylight simulation methods}

These sophisticated daylight metrics, introduced in section 4.1, are realised by the support of effective simulation tools. Different simulation tools along with their underling algorithms, sky models, capability and other related information are summarised in Table 4. 
Table 4: Daylight simulation tools

\begin{tabular}{|c|c|c|c|c|c|c|}
\hline $\begin{array}{l}\text { Simulation } \\
\text { software }\end{array}$ & Algorithms & Sky model & $\begin{array}{l}\text { Dynamic } \\
\text { simulatio } \\
\text { n }\end{array}$ & $\begin{array}{l}\text { photoreal } \\
\text { istic } \\
\text { rendering }\end{array}$ & Note & $\begin{array}{l}\text { Reference for } \\
\text { complex } \\
\text { window } \\
\text { application } \\
\end{array}$ \\
\hline RADIANCE & $\begin{array}{l}\text { backward ray- } \\
\text { tracing }\end{array}$ & $\begin{array}{l}\text { all weather } \\
\text { sky model }\end{array}$ & yes & yes & & $\begin{array}{l}{[112, \quad 148,} \\
154]\end{array}$ \\
\hline Daysim & $\begin{array}{l}\text { backward ray- } \\
\text { tracing }\end{array}$ & $\begin{array}{l}\text { all weather } \\
\text { sky model }\end{array}$ & yes & yes & $\begin{array}{lr}\text { a } r \text { RADIANCE- } \\
\text { based method } \\
\text { with } \\
\text { interface }\end{array}$ & $\begin{array}{l}{[122,123,} \\
125-127]\end{array}$ \\
\hline $\begin{array}{l}\text { 3DS Max } \\
\text { Design }\end{array}$ & ray-tracing & $\begin{array}{l}\text { all weather } \\
\text { sky model }\end{array}$ & yes & yes & & [124] \\
\hline Lightsolve & $\begin{array}{lr}\text { combines } & \\
\text { forward ray } \\
\text { tracing } \quad \text { with } \\
\text { radiosity and } \\
\text { shadow volumes } \\
\text { rendering [155] }\end{array}$ & $\begin{array}{l}\text { all weather } \\
\text { sky model }\end{array}$ & yes & yes & $\begin{array}{lr}\text { a } & \text { goal-based } \\
\text { approach } & \text { to } \\
\text { support } & \text { daylight } \\
\text { design } & \text { during } \\
\text { early } & \text { design } \\
\text { stages } & \\
\end{array}$ & [155-157] \\
\hline $\begin{array}{l}\text { Daylight } \\
\text { visualiser }\end{array}$ & $\begin{array}{l}\text { ray-tracing } \\
\text { method [137] }\end{array}$ & $\begin{array}{l}\text { CIE } \\
\text { standard } \\
\text { sky models }\end{array}$ & no & yes & $\begin{array}{l}\text { predicting } \\
\text { daylight levels } \\
\text { and appearance } \\
\text { prior at building } \\
\text { design stages }\end{array}$ & [137] \\
\hline DIAlux & $\begin{array}{l}\text { version DIAlux } \\
4 \text { uses radiosity } \\
\text { method; version } \\
\text { DIAlux evo uses } \\
\text { photon shooting } \\
\text { method [158] }\end{array}$ & $\begin{array}{l}\text { CIE } \\
\text { standard } \\
\text { sky models }\end{array}$ & no & yes & $\begin{array}{l}\text { mainly used for } \\
\text { electric lighting } \\
\text { design practice }\end{array}$ & [159] \\
\hline Lightscape & $\begin{array}{l}\text { radiosity and } \\
\text { ray-tracing } \\
\text { algorithms, use } \\
\text { only } \\
\text { radiosity } \\
\text { solution for the } \\
\text { quantitative } \\
\text { results }\end{array}$ & & & yes & $\begin{array}{l}\text { lighting design } \\
\text { and rendering tool }\end{array}$ & {$[160]$} \\
\hline EnergyPlus & $\begin{array}{l}\text { radiosity and } \\
\text { split-flux } \\
\text { method }\end{array}$ & $\begin{array}{l}\text { all weather } \\
\text { sky model }\end{array}$ & yes & no & $\begin{array}{l}\text { overall building } \\
\text { performance } \\
\text { simulation engine }\end{array}$ & [161-163] \\
\hline IES & $\begin{array}{l}\text { backward ray- } \\
\text { tracing }\end{array}$ & $\begin{array}{l}\text { all weather } \\
\text { sky model }\end{array}$ & yes & yes & $\begin{array}{l}\text { a RADIANCE- } \\
\text { based method } \\
\text { integrated into } \\
\text { energy model }\end{array}$ & {$[164]$} \\
\hline $\begin{array}{l}\text { Design } \\
\text { Builder }\end{array}$ & $\begin{array}{l}\text { backward ray- } \\
\text { tracing }\end{array}$ & $\begin{array}{l}\text { all weather } \\
\text { sky model }\end{array}$ & yes & yes & $\begin{array}{l}\text { a RADIANCE- } \\
\text { based method } \\
\text { integrated into } \\
\text { energy model }\end{array}$ & {$[160]$} \\
\hline Ecotect & $\begin{array}{l}\text { backward ray- } \\
\text { tracing }\end{array}$ & $\begin{array}{l}\text { all weather } \\
\text { sky model }\end{array}$ & yes & no & $\begin{array}{l}\text { a RADIANCE- } \\
\text { based method } \\
\text { integrated into } \\
\text { energy model, no } \\
\text { longer on the } \\
\text { market }\end{array}$ & {$[165]$} \\
\hline $\begin{array}{l}\text { DIVA for } \\
\text { Rhino }\end{array}$ & $\begin{array}{l}\text { backward ray- } \\
\text { tracing }\end{array}$ & $\begin{array}{l}\text { all weather } \\
\text { sky model }\end{array}$ & yes & yes & $\begin{array}{l}\text { a RADIANCE- } \\
\text { based method } \\
\text { integrated into } \\
\text { energy model }\end{array}$ & [161] \\
\hline
\end{tabular}


As shown in Table 4, various daylight simulation tools are available for both academic research and engineering practice. These simulation tools can be classified into the following categories according to their main purposes of use:

1. Specialised daylight simulation tools: e.g. RADIANCE and Daysim. RADIANCE is an open-source and research grade tool for visualising daylight and artificial light in virtual environments [110]. The results from RADIANCE have been validated by several studies $[100,118-120]$ and it is regarded by many professionals as the most accurate daylight simulation tool $[100,166]$. However, widespread use of RADIANCE has been hindered due to its relative complexity, which means that the tool takes time to master due to its lacking a graphical user interface, which hindered the effective input of data [167]. In order to take advantage of the algorithms provided by RADIANCE, and make it much easier for users to operate, a number of commercial software modules have been developed based on RADIANCE simulation engine, such as Daysim. A daylight coefficient approach combined with the Perez all weather sky model is used for annual dynamic daylight calculation in Daysim. Using Daysim to conduct daylight simulation has also been validated [168].

2. Architecture photorealistic rendering tools: e.g. 3DS Max Design. 3DS Max is commonly used by architects and film or game designers. The 3DS Max Design version includes a lighting simulation module based on Exposure ${ }^{\mathrm{TM}}$ technology [160]. In addition to photorealistic renderings, 3DS Max Design also outputs hourly illuminance value and Daylight Factors at each calculation point, which makes the results suitable for quantitative analysis.

3. Early design stage tools: e.g. Lightsolve and Daylight visualiser. Software that supports professionals at an early design stage by simulating luminance environment, predicting daylight levels and rendering the appearance of a daylit space prior to implement building design $[155,156]$.

4. Lighting design tools: e.g. DIAlux and Lightscape. Software that mainly used to calculate and visualise artificial lighting and calculate electric energy performance. These can also be used for daylight calculation and visualisation.

5. Daylight section in energy simulation tools: e.g. EnergyPlus, IES, Ecotect, Design Builder and DIVA-for-Rhino. Coupled daylight analysis in energy simulation programs can benefit users by providing multiple building performance predictions using only one model, thus saving time on using different tools to build different models [169]. A large 
number of these energy tools use RADIANCE as the simulation engine of their daylight module, such as IES, Ecotect, Design Builder and DIVA-for-Rhino.

Although, daylight simulation tools can be used for different purposes, the underlying simulation algorithms concentrate on a limited number. Currently, ray-tracing algorithms and radiosity algorithms are the most implementable approaches for realising daylight simulation [169]. Other methods, such as split-flux, phono mapping methods, are also evident implemented in daylight simulation tools [160].

The radiosity technique subdivides reflecting surfaces into nodal patches, and makes use of view factors applied to pairs of nodal patches to create a greater accuracy in determining the overall contributing factor of reflected light within a space [79]. As in radiosity models, each patch is considered as a Lambertian reflector, which means that this method cannot model specular reflection effectively $[90,100,119,120,166,170]$. The lighting design tool, Lightscape, and energy simulation tool, EnergyPlus, use radiosity techniques in their daylighting calculation module [160].

In ray-tracing methods, each ray carries a 'weight', which is proportional to the intensity of the corresponding ray. The rays are traced from the light source to each striking surfaces in the scene (forward ray-tracing) or from the point of interest in the screen to the light source (backward ray-tracing). After striking on a surface, new rays are generated and their weight depends on the surface reflectivity [78]. Further action will be terminated if the weight of a ray falls below a threshold and the process is repeated with another emission [78]. RAIDANCE, which has been developed by Greg Ward at Lawrence Berkeley National Laboratories, is based on a backward ray-tracing algorithm (Monte Carlo ray-tracer) [171].

Some of the daylight simulation tools mentioned above (e.g. RADIANCE, Daysim and DIVA for Rhino) have been used to predict the daylighting performance of rooms served by complex window systems $[112,123,154,161]$. Sun et al [112] used RADIANCE to investigate the annual daylight performance of a window system integrated with interstitial Parallel Slat Transparent Insulation Material (PS-TIM) applied to an office simulated with different glazing orientations and under different climatic scenarios. Their simulation results suggest that applying (PS-TIM) can increase the percentage of annual working hours under useful daylight illuminance (UDI), where the illuminance lies in the useful range by up to $79 \%$. It also effectively reduces the probability of glare. The optimal PS-TIM structure geometry is affected by site altitude, orientations and local prevailing sky conditions. Gong et al. [154] used RADIANCE to evaluate the daylight performance of a space served by a 
multifunctional complex fenestration system with embedded micro-mirrors in a south-facing façade in Lausanne, Switzerland. They concluded that, the risk of glare was reduced on the spring equinox and on the winter solstice when applying micro-mirrors in the upper twothirds of the glazing. The directivity of daylight along the depth of the room was significantly improved if the micro-mirrors were applied across the whole area of glazing. Li et al. [123] used EnergyPlus and Daysim to investigate the performance of a building integrated solar thermal shading (BISTS) system on building energy consumption and daylight levels under the climatic conditions for Los Angeles, USA. They concluded that BISTS can increase the useful daylight level in a single perimeter room and achieve a 5.3\% primary energy saving. Yun et al. [161] proposed lighting and shading control strategies and used DIVA for Rhino and EnergyPlus to evaluate improvements in visual comfort level and building energy saving under the climatic conditions for Incheon, Korea. The glazing in their simulation contained a blind structure and their simulation results show that for a fixed blind slat angle of $0^{\circ}$ dynamic shading is good in winter, while a fixed blind slat angle of $30^{\circ}$ provided good dynamic shading in summer. 


\section{Energy performance prediction for buildings with complex fenestration systems}

Many building simulation tools, such as EnergyPlus, ESP-r, IES, IDA ICE, TRNSYS, and TAS can be used to explore the energy, thermal and daylight performance of buildings with complex fenestration systems. The challenges related to the use of these tools for modelling complex fenestration systems include: 1) precise characterisation of the thermal and optical properties of fenestration systems, in which two- or three-dimensional heat transfer and/or light transmittance might exist due to the presence of complex structural geometries; 2) the potential need to model adaptive features associated with the operation of complex fenestration systems (e.g. switchable glazing, moveable shading, etc.), that may affect a number of properties (e.g. thermal, visual) simultaneously. However, most of the current tools assume only 1D transfer for thermal flow and/or solar/visible flux [172].

Advanced window systems that employ adaptive components require users to develop custom-made scripts within the software interface or to access and modify its source code [173]. Building performance simulation tools that allow source code access and modification include: EnergyPlus, ESP-r, IDA ICE and TRNSYS [173]. Of these four tools, EnergyPlus has the strongest capabilities to model complex window systems as $2 \mathrm{D}$ or $3 \mathrm{D}$ thermal or optical entities (e.g. through use of BSDFs) [173]. It also supports the inclusion of linking sensors, control logic and actuators to allow windows with adaptive features to be modelled through the use of EnergyPlus Runtime Language (ERL) [174]. Thus, this section of the review focuses EnergyPlus, and uses it as an example to explore how complex glazing systems may be accommodated within a comprehensive energy simulation of a building.

In much of the literature dealing with the application of EnergyPlus to the simulation of glazing systems, the glazing has been modelled using a simplified method: a schematic diagram detailing the heat transfer in a double glazing system is presented in Figure 11(a). The heat balance equation for each of the glazing unit's surfaces can be written as [2]:

$$
\begin{gathered}
E_{o} \varepsilon_{1}-\varepsilon_{1} \sigma T_{1}^{4}+k_{1}\left(T_{2}-T_{1}\right)+h_{o}\left(T_{o}-T_{1}\right)+S_{1}=0 \\
k_{1}\left(T_{1}-T_{2}\right)+h_{g}\left(T_{3}-T_{2}\right)+\sigma \frac{\varepsilon_{3} \varepsilon_{2}}{1-\left(1-\varepsilon_{2}\right)\left(1-\varepsilon_{3}\right)}\left(T_{3}^{4}-T_{2}^{4}\right)+S_{2}=0 \\
k_{1}\left(T_{4}-T_{3}\right)+h_{g}\left(T_{2}-T_{3}\right)+\sigma \frac{\varepsilon_{2} \varepsilon_{3}}{1-\left(1-\varepsilon_{3}\right)\left(1-\varepsilon_{2}\right)}\left(T_{2}^{4}-T_{3}^{4}\right)+S_{3}=0
\end{gathered}
$$




$$
E_{i} \varepsilon_{4}-\varepsilon_{4} \sigma T_{4}^{4}+k_{2}\left(T_{3}-T_{4}\right)+h_{i}\left(T_{i}-T_{4}\right)+S_{4}=0
$$

When a complex structure is present in the space between the panes, the twodimensional heat transfer process can be represented by a single solid layer (illustrated in Figure 11 (b)) using a function built into the software. This default method can be refined by integrating expressions that characterise the behaviour of the glazing unit under changing environmental conditions, such as ambient temperature. These are often in the form of regression equations derived from measured data or data determined from numerical studies such as CFD [172].

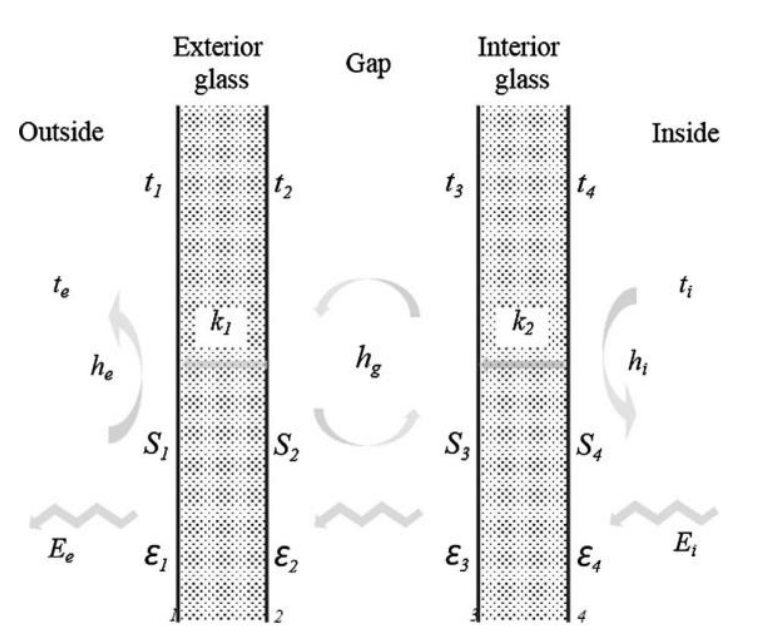

(a)

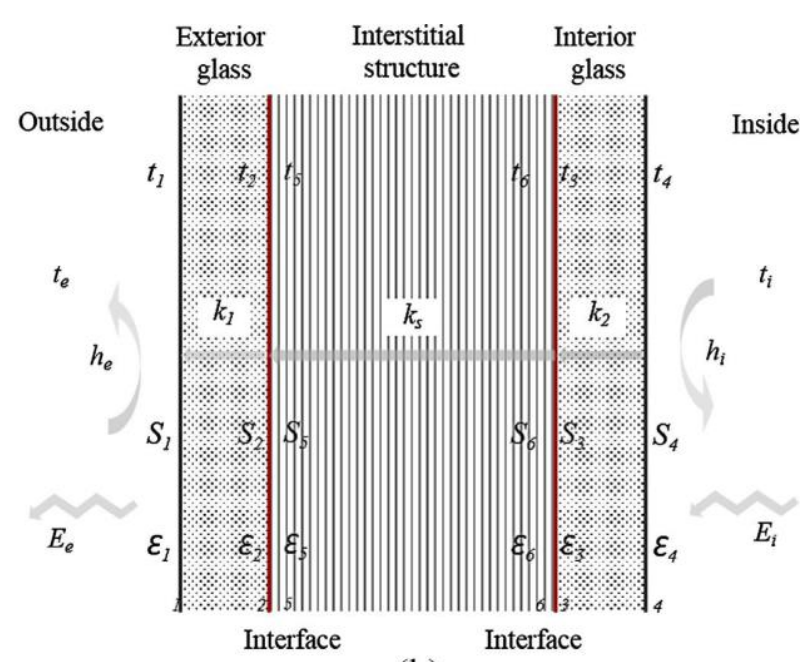

(b)

Figure 11. Illustration of heat transfer and the variables used in heat balance equations for (a) double-glazed windows (b) double glazed window systems with an interstitial structure [2]

When there is no shading device or there is a plain shade or window screen present, the optical properties are defined simply by areas and solar and visible transmittance/reflectance; when the windows are integrated with internal, external or interstitial Venetian blinds, the optical properties of the window system are obtained using a radiosity-based pre-computation of solar heat gain coefficient and visible transmittance based on the blind's geometry and slat surface properties. When solving for heat transfer through fenestration systems within EnergyPlus, the heat flow is assumed to be one dimensional and perpendicular to the glazing panes.

As an example of the latter approach, Yun et al.[161] investigated the building energy performance and the daylight performance of an office using the climatic data for Seoul, South Korea. Venetian blinds with "fixed shading control" (i.e. slats positioned at orientation angles varying from $0^{\circ}, 15^{\circ}$ and $30^{\circ}$ to the horizontal) and "dynamic shading control" (i.e. automatic control of the slat tilt angle) were applied to a window. The optical properties of 
window with Venetian blinds were obtained using a radiosity-based pre-computation of solar heat gain coefficient and visible transmittance based on the slat width, slat pitch and slat reflectance, as well as the slat tilt angles. Their results revealed that when the slats were tilted at $30^{\circ}$ or when dynamic shading was used, energy saving and anti-glare control can be achieved during summer time. Using a similar method, Yoon et al. [175] investigated how the reflectance of external and internal blinds influenced the heat balance and overall energy performance of a room located in Daejeon City in South Korea. They concluded that a reduction in the reflectance of interior blinds resulted in a decrease in heating load and an increase in cooling load. The opposite pattern of behaviour was observed for the external blinds. The approach adopted in this study captures only part of the behaviour of complex glazing systems, such as Venetian blinds. The main omission relates to the time dependent variation in the incidence of the direct radiation component. Its transmission through Venetian blinds (and other complex systems, such as tubular shading structures or nonlinear shading systems) is sensitive to incidence angle and failing to account for it accurately can result in errors in both the predicted luminous and thermal environment in the space they protect. The launch of EnergyPlus V7.2 allowed for the inclusion of Bidirectional Scattering Distribution Functions (BSDF) in the modelling process, and this has significantly enhanced the software's capability to predict building energy and daylight performance of spaces employing complex fenestration systems. However, published articles related to the use of BSDFs in EnergyPlus are not common. This is, in large part, due to the challenge of obtaining the specific BSDF data for window system. These may be predicted using RADIANCE and imported into EnergyPlus while the software WINDOW establishes a bridge between these two software packages. Fernandes et al. [162] have undertaken accurate modelling of complex fenestration systems using BSDFs in a study to quantify the potential energy saving and peak cooling demand reduction achieved by applying angular selective window systems (i.e. expanded metal mesh, a tubular shading structure, and a micro-perforated screen) in a whole-building simulation. The results revealed that energy savings of between $28 \sim 47 \%$ may be achieved in the perimeter zone under the climates of Chicago and Houston in the USA. Hoffmann et al. [163] investigated the impact of twelve different shading devices on whole building energy performance under two climates (the moderate climate of San Francisco and a hot and dry Southern California climate). They used their study to develop optimised strategies to balance solar gain with glare and daylight levels. The optical properties of the shading systems were accurately defined using the BSDF method and hourly scheduled surface gains. The results showed that shading geometry and slat material 
characteristics significantly affected the amount of heat gain from solar radiation and distribution of transmitted daylight.

When dealing with an adaptive fenestration system, the ability to modify window thermo-optical properties to counter temporary changes in energy fluxes incident on the building need to be accommodated. Firlag, et al. [176] investigated the use of dynamic control algorithms implemented using the Energy Management System in EnergyPlus to control two shading devices (an external roller blind mounted to a double-glazed window and an inter-pane cellular shading device with a triple-glazed window) that were applied to a typical residential building under four different climates (those for Atlanta, Minneapolis, Phoenix and Washington DC). They also used BSDF data as a precise description of these complex window systems with dynamic controls. It was concluded that using automated shading devices with proposed control algorithms can reduce solar heat gain, resulting 11.6 $\sim 13.0 \%$ reduction in building energy consumption. Loonen and et al. [173] reviewed available building performance simulation tools that can be used to model adaptive fenestration systems or façades. They discussed the requirement for successfully realising modelling and simulation of adaptive systems, compared five commonly used simulation software tools and proposed further development opportunities in this field.

The authors $[2,61,112,177]$ proposed a comprehensive approach to investigate the thermal and optical performance of a window system with Transparent Insulation Materials (TIMs) and also how they shape the daylight and energy performance of the buildings they are applied to. The dynamic thermal conductance across the glazing system caused by variation of environmental conditions were obtained from parametric studies made using Computational Fluid Dynamics simulation [61]. Regression was used on the results to determine equations that were integrated into EnergyPlus to represent the window's thermal characteristics in building simulation [2, 177]. Meanwhile, a ray-tracing technique is used to predict the optical characteristics that were formatted into BSDF data. RADIANCE was used to generate a comprehensive picture of daylight performance when applying window systems with TIMs through the generation of dynamic building daylight metrics [112]. The BSDF data were also input into the building simulation tool (i.e. EnergyPlus) to predict solar gains. Then, the developed model was used to obtain relatively accurate building heating, cooling and lighting energy estimates, when glazing systems with Parallel Slats Transparent Insulation Materials (PS-TIMs) are applied within a window [2, 177]. The simulation results show that when compared with a conventional double glazed system, the application of PS- 
TIMs can result in a more visually comfortable and uniformly lit environment, which might be desired in an office space. Applying PS-TIM was also shown to result in a reduction in energy consumption of up to $35.8 \%$.

\section{Conclusion}

Comprehensive models that seek to quantify the contribution that complex window systems make to building performance need to include:

- a characterisation of their temperature driven thermal behaviour;

- a characterisation of the radiative transfer to quantify solar gain;

- a characterisation of the radiative transfer to quantify the daylit luminous environment;

- a link to an artificial lighting model that will adjust the contribution it makes to the luminous environment in response to the availability of daylight.

This review focuses on the thermal and optical characterisation of complex window systems as well as comprehensive building simulation approaches made possible through the coupling of RADIANCE and EnergyPlus.

Methods for determining the optical properties of window systems, especially those incorporating complex structures have been reviewed. The radiosity method is a commonly utilised, effective approach to determine the optical performance of simple window systems in order to obtain transmittance or reflectance. However, when considering the strong directional effects that complex interstitial structures can impose on the distribution of solar or daylight flux, radiosity approaches prove inappropriate and alternative approaches are required to accurately predict the luminous environment of the space. An alternative method, which uses a matrix of Bidirectional Scattering Distribution Functions (BSDFs) to characterise the optical properties of complex window systems, was proposed and validated in the literature. These angularly resolved transmittance or reflectance data are capable of describing the behaviours of window systems with complex interstitial structures; and can be obtained via three-dimensional ray-tracing methods.

Having determined BSDFs, ray-tracing techniques may then be used to quantify the visual environment of a space illuminated by daylight via advanced glazing systems. In addition to visualising the luminous environment, recently developed climate specific daylighting metrics are able to offer a more comprehensive picture quantifying the qualities 
of the luminous environment. As such, they form an effective complement to the BSDF approach to designing spaces lit via advanced glazing systems.

Comprehensive studies of building energy demand require accurate characterisation of the thermal behaviour of advanced glazing systems as well as a comprehensive picture of their luminous behaviour that may be coupled to artificial lighting control models. The ability to import thermal characterization into tools such as EnergyPlus as well as the ability to couple the tool to lighting tools such as RADIANCE creates a framework where such studies may be undertaken.

\section{Acknowledgements}

This work was supported by the Faculty of Engineering, University of Nottingham and the China Scholarship Council through a joint PhD studentship awarded to Yanyi Sun. 


\section{References}

[1] Huang Y, Niu J-1, Chung T-m. Comprehensive analysis on thermal and daylighting performance of glazing and shading designs on office building envelope in cooling-dominant climates. Applied Energy. 2014;134:215-28.

[2] Sun Y, Liang R, Wu Y, Wilson R, Rutherford P. Development of a comprehensive method to analyse glazing systems with Parallel Slat Transparent Insulation material (PS-TIM). Applied Energy. 2017;205:951-63.

[3] Cuce E, Riffat SB. A state-of-the-art review on innovative glazing technologies. Renewable and Sustainable Energy Reviews. 2015;41:695-714.

[4] Gratia E, De Herde A. Natural cooling strategies efficiency in an office building with a double-skin façade. Energy and Buildings. 2004;36:1139-52.

[5] Ding W, Hasemi Y, Yamada T. Natural ventilation performance of a double-skin façade with a solar chimney. Energy and Buildings. 2005;37:411-8.

[6] Shameri MA, Alghoul MA, Sopian K, Zain MFM, Elayeb O. Perspectives of double skin façade systems in buildings and energy saving. Renewable and Sustainable Energy Reviews. 2011;15:1468-75.

[7] Giorgi LD, Bertola V, Cafaro E. Thermal convection in double glazed windows with structured gap. Energy and Buildings. 2011;43:2034-8.

[8] Xamán J, Olazo-Gómez Y, Chávez Y, Hinojosa JF, Hernández-Pérez I, Hernández-López I, et al. Computational fluid dynamics for thermal evaluation of a room with a double glazing window with a solar control film. Renewable Energy. 2016;94:237-50.

[9] Oleskowicz-Popiel C, Sobczak M. Effect of the roller blinds on heat losses through a double-glazing window during heating season in Central Europe. Energy and Buildings. 2014;73:48-58.

[10] Zhang C, Wang J, Xu X, Zou F, Yu J. Modeling and thermal performance evaluation of a switchable triple glazing exhaust air window. Applied Thermal Engineering. 2016;92:8-17. [11] Amaral AR, Rodrigues E, Gaspar AR, Gomes Á. A thermal performance parametric study of window type, orientation, size and shadowing effect. Sustainable Cities and Society. 2016.

[12] Konroyd-Bolden E, Liao Z. Thermal window insulation. Energy and Buildings. 2015;109:245-54.

[13] Konstantzos I, Tzempelikos A, Chan Y-C. Experimental and simulation analysis of daylight glare probability in offices with dynamic window shades. Building and Environment. 2015;87:244-54.

[14] Piccolo A, Simone F. Effect of switchable glazing on discomfort glare from windows. Building and Environment. 2009;44:1171-80.

[15] Karlsen L, Heiselberg P, Bryn I, Johra H. Verification of simple illuminance based measures for indication of discomfort glare from windows. Building and Environment. 2015;92:615-26.

[16] Shih N-J, Huang Y-S. An analysis and simulation of curtain wall reflection glare. Building and Environment. 2001;36:619-26.

[17] Bernier M, Hallé S. A critical look at the air infiltration term in the canadian energy rating procedure for windows. Energy and Buildings. 2005;37:997-1006.

[18] Bakonyi D, Dobszay G. Simulation aided optimization of a historic window's refurbishment. Energy and Buildings. 2016;126:51-69.

[19] Russell M. Sanders, Hargrove CA. Preventing and Treating Failure in Glazed Curtain Wall Systems. Journal of architectural technology. 2012;29:1-8.

[20] Nielson KJ. Interior textiles: fabrics, applications and historical styles: Hoboken, N.J. : Hohn Wiley \& Sons; 2007. 
[21] ISO. 12567-1: Thermal performance of windows and doors -- Determination of thermal transmittance by the hot-box method -- Part 1: Complete windows and doors. 2012.

[22] ISO. 9869-1: Thermal insulation -- Building elements -- In-situ measurement of thermal resistance and thermal transmittance Part 1: Heat flow meter method. 2014.

[23] ISO. 8990: Thermal insulation - determination of steady-state thermal transmission properties - calibrated and guarded hot box. . 1996.

[24] ISO. 8301: Thermal insulation -- Determination of steady-state thermal resistance and related properties -- Heat flow meter apparatus. 1991

[25] ISO. 8302:Thermal insulation -- Determination of steady-state thermal resistance and related properties -- Guarded hot plate apparatus. 1991.

[26] ASTM. C1363: Standard Test Method for Thermal Performance of Building Materials and Envelope Assemblies by Means of a Hot Box Apparatus. 2011.

[27] ASTM. C1199: Standard test method for measuring the steady-state thermal transmittance of fenestration systems using hot box methods. . 2009.

[28] ASTM. C1046: Standard Practice for In-Situ Measurement of Heat Flux and Temperature on Building Envelope Components. 2013.

[29] EN. 674: Glass in building-- Determination of thermal transmittance (U value) -Guarded hot plate method. 2011

[30] EN. 675: Glass in building. Determination of thermal transmittance (U value). Heat flow meter method. 2011

[31] EN. 1946-2: Thermal performance of building products and components. Specific criteria for the assessment of laboratories measuring heat transfer properties. Measurements by guarded hot plate method. 1999 .

[32] EN. 1946-3: Thermal performance of building products and components. Specific criteria for the assessment of laboratories measuring heat transfer properties. Measurements by heat flow meter method. 1999.

[33] GOST. 26602.1: Windows and doors. Methods of determination of resistance of thermal transmission. 1999.

[34] Goetzberger A. Transparent Insulation Technology for Solar Energy Conversion (second ed.). Freiburg: Fraunhofer Institute for Solar Energy Systems; 1991.

[35] Platzer WJ. Calculation procedure for collectors with a honeycomb cover of rectangular cross section. Solar Energy. 1992;48.

[36] Platzer WJ. Total heat transport data for plastic honeycomb-type structures. Solar Energy 1992;49:351-8.

[37] Suehrcke H, Däldehög D, Harris JA, Lowe RW. Heat transfer across corrugated sheets and honeycomb transparent insulation. Solar Energy. 2004;76:351-8.

[38] Yesilata B, Turgut P. A simple dynamic measurement technique for comparing thermal insulation performances of anisotropic building materials. Energy and Buildings. 2007;39:1027-34.

[39] Baldinelli G, Bianchi F. Windows thermal resistance: Infrared thermography aided comparative analysis among finite volumes simulations and experimental methods. Applied Energy. 2014;136:250-8.

[40] Asdrubali F, Baldinelli G. Thermal transmittance measurements with the hot box method: Calibration, experimental procedures, and uncertainty analyses of three different approaches. Energy and Buildings. 2011;43:1618-26.

[41] Sassine E. A practical method for in-situ thermal characterization of walls. Case Studies in Thermal Engineering. 2016;8:84-93. 
[42] Cattarin G, Causone F, Kindinis A, Pagliano L. Outdoor test cells for building envelope experimental characterisation - A literature review. Renewable and Sustainable Energy Reviews. 2016;54:606-25.

[43] ISO. 10292: Glass in building -- Calculation of steady-state U values (thermal transmittance) of multiple glazing. 1994.

[44] ISO. 15099: Thermal performance of windows, doors and shading devices -- Detailed calculations. 2003.

[45] EN. 673: Glass in building-- Determination of thermal transmittance (U value) Calculation method. 2011

[46] Jelle BP, Kalnæs SE, Gao T. Low-emissivity materials for building applications: A stateof-the-art review and future research perspectives. Energy and Buildings. 2015;96:329-56.

[47] ISO. 10077-1:Thermal performance of windows, doors and shutters -- Calculation of thermal transmittance -- Part 1: General. 2006.

[48] ISO. 10077-2: Thermal performance of windows, doors and shutters - calculation of thermal transmittance - numerical method for frames. 2003.

[49] NFRC. 100-2010: Procedure for Determining Fenestration Product U-factors. 2010.

[50] ASHRAE. Standard Method for Determining and Expressing the Heat Transfer and

Total Optical Properties of Fenestration Products. Public Review Draft of Standard Atlanta, 1998.

[51] Blanusa P, Goss WP, Roth H, Weitzmannn P, Jensen CF, Svendsen S, et al. Comparison between ASHRAE and ISO thermal transmittance calculation methods. Energy and Buildings. 2007;39:374-84.

[52] Zhao Y, Curcija D, Gross WP. Prediction of multicellular flow regime of natural convection in fenestration glazing cavities. ASHRAE Transactions. 1997;103:1-12.

[53] Gan G. Thermal transmittance of multiple glazing: computational fluid dynamics prediction. Applied Thermal Engineering. 2001;21:1583-92.

[54] Wright JL, Sullivan FF. A two-dimensional numerical model for natural convection in a vertical rectangular window cavity. ASHRAE Transactions. 1993;99:1193-206.

[55] Ganguli AA, Pandit AB, Joshi JB. CFD simulation of heat transfer in a two-dimensional vertical enclosure. Chemical Engineering Research and Design. 2009;87:711-27.

[56] Ganguli AA, Pandit AB, Joshi JB. Numerical predictions of flow patterns due to natural convection in a vertical slot. Chemical Engineering Science. 2007;62:4479-95.

[57] Dalal R, D. Naylor, Roeleveld D. A CFD study of convection in a double glazed window with an enclosed pleated blind. Energy and Buildings. 2009;41:1256-62.

[58] Avedissian T, Naylor D. Free convective heat transfer in an enclosure with an internal louvered blind International Journal of Heat and Mass Transfer. 2008;51:283-93.

[59] Naylor D, Collins M. Evaluation of an Approximate Method for Predicting The U-value of a Window with a between-Panes Blind. Numerical Heat Transfer, Part A: Applications. 2005;47:233-50.

[60] Collins M, Tasnim S, Wright J. Numerical analysis of convective heat transfer in fenestration with between-the-glass louvered shades. Building and Environment. 2009; 44:2185-92.

[61] Sun Y, Wu Y, Wilson R, Sun S. Thermal evaluation of a double glazing façade system with integrated Parallel Slat Transparent Insulation Material (PS-TIM). Building and Environment. 2016;105:69-81.

[62] Almeida F, Naylor D. Experimental study of free convection in a window with a heated between-panes blind. Energy and Buildings. 2011;43:2647-55.

[63] Naylor D, Lai BY. Experimental Study of Natural Convection in a Window with a Between-Panes Venetian Blind. Experimental Heat Transfer. 2007;20:1-17. 
[64] Wright JL, Jin H, Hollands KGT, Naylor D. Flow visualization of natural convection in a tall, air-filled vertical cavity. International Journal of Heat and Mass Transfer. 2006;49:889904.

[65] Sun Y, Wu Y, Wilson R, Lu S. Experimental measurement and numerical simulation of the thermal performance of a double glazing system with an interstitial Venetian blind. Building and Environment. 2016 103:111-22.

[66] ISO. 9050: Glass in building. Determination of light transmittance, solar direct transmittance, total solar energy transmittance, ultraviolet transmittance and related glazing factors. 2003.

[67] EN. 410: Glass in building. Determination of luminous and solar characteristics of glazing. 2011.

[68] CIE. No. 130. Practical methods for the measurement of reflectance and transmittance. 1998.

[69] Jonsson JC. Optical measurement techniques for complex fenestration systems (CFS). Radiance workshop2011.

[70] Jonsson A, Roos A, Jonson EK. The effect on transparency and light scattering of dip coated antireflection coatings on window glass and electrochromic foil. Solar Energy Materials and Solar Cells. 2010;94:992-7.

[71] Long L, Ye H, Zhang H, Gao Y. Performance demonstration and simulation of thermochromic double glazing in building applications. Solar Energy. 2015;120:55-64.

[72] Ye H, Long L, Zhang H, Xu B, Gao Y, Kang L, et al. The demonstration and simulation of the application performance of the vanadium dioxide single glazing. Solar Energy Materials and Solar Cells. 2013;117:168-73.

[73] Goia F, Zinzi M, Carnielo E, Serra V. Spectral and angular solar properties of a PCMfilled double glazing unit. Energy and Buildings. 2015;87:302-12.

[74] Gowreesunker BL, Stankovic SB, Tassou SA, Kyriacou PA. Experimental and numerical investigations of the optical and thermal aspects of a PCM-glazed unit. Energy and Buildings. 2013;61:239-49.

[75] Xiao Liu, Hao Gao, Yanyi Sun, Yupeng Wu, Benjamin Martin, John Chilton, et al. Thermal and optical analysis of a passive heat recovery and storage system for greenhouse façade/roof. Procedia Engineering. 2016;155:471-8.

[76] Gao T, Ihara T, Grynning S, Jelle BP, Lien AG. Perspective of aerogel glazings in energy efficient buildings. Building and Environment. 2016;95:405-13.

[77] Berardi U. Development of Glazing Systems with Silica Aerogel. Energy Procedia. 2015;78:394-9.

[78] Tsangrassoulis A, Bourdakis V. Comparison of radiosity and ray-tracing techniques with a practical design procedure for the prediction of daylight levels in atria. Renewable Energy. 2003;28:2157-62.

[79] EnergyPlus. Engineering Reference. 2013.

[80] Xu X-1, Yang Z. Natural ventilation in the double skin facade with venetian blind. Energy and Buildings. 2008;40:1498-504.

[81] Kotey NA, Collins MR, Wright JL, Jiang T. A Simplified Method for Calculating the Effective Solar Optical Properties of a Venetian Blind Layer for Building Energy Simulation. Journal of Solar Energy Engineering. 2009;131:021002.

[82] Gomes MG, Rodrigues AM, Bogas JA. Numerical and experimental study of the optical properties of venetian blinds. Journal of Building Physics. 2012;36:7-34.

[83] Gomes MG, Santos AJ, Rodrigues AM. Solar and visible optical properties of glazing systems with venetian blinds: Numerical, experimental and blind control study. Building and Environment. 2014;71:47-59. 
[84] Chaiyapinunt S, Khamporn N. Shortwave thermal performance for a glass window with a curved venetian blind. Solar Energy. 2013;91:174-85.

[85] Chaiyapinunt S, Worasinchai S. Development of a mathematical model for a curved slat venetian blind with thickness. Solar Energy. 2009;83:1093-113.

[86] Somsak Chaiyapinunt, Nopparat Khamporn. Heat transmission through a glass window with a curved venetian blind installed. Solar Energy. 2014;110:71-82.

[87] Somsak Chaiyapinunt, Worasinchai S. Development of a model for calculating the longwave optical properties and surface temperature of a curved venetian blind. Solar-Energy. 2009;83:817-31.

[88] Tzempelikos A. The impact of venetian blind geometry and tilt angle on view, direct light transmission and interior illuminance. Solar Energy. 2008;82:1172-91.

[89] Wang Y, Chen Y, Guo X, He W, Gao L. Development of a Solar Control Method of the Venetian Blinds. Procedia Engineering. 2015;121:1186-92.

[90] Chan Y-C, Tzempelikos A. A hybrid ray-tracing and radiosity method for calculating radiation transport and illuminance distribution in spaces with venetian blinds. Solar Energy. 2012;86:3109-24.

[91] Wang Y, Chen Y. Modeling and calculation of solar gains through multi-glazing facades with specular reflection of venetian blind. Solar Energy. 2016;130:33-45.

[92] Klems JH. A new method for predicting the solar heat gain of complex fenestration systems II. detailed description of the matrix layer calculation. ASHRAE Transactions. 1994;100.

[93] Klems JH. A new method for predicting the solar heat gain of complex fenestration systems - 1, overview and derivation of the matrix layer calculation. ASHRAE Transactions. $1994 ; 100$.

[94] Ward G, Mistrick R, Lee ES, McNeil A, Jonsson J. Simulating the daylight performance of Complex Fenestration Systems using Bidirectional Scattering Distribution Functions within Radiance. Journal of the Illuminating Engineering Society of North America 2011;7. [95] Andersen M, de Boer J. Goniophotometry and assessment of bidirectional photometric properties of complex fenestration systems. Energy and Buildings. 2006;38:836-48.

[96] Andersen M, de Boer J. Goniophototmetry and assessment of bidirectional photometric properties of complex fenestration systems. IEA SHC TASK 31, Daylighting buildings in the 21 st century. Stuttgart, Germany2005.

[97] G. Ward. Measuring and modeling anisotropic reflection. ACM SIGGRAPH Computer Graphics. 1992;26:265-72.

[98] Andersen M, Rubin M, Powles R, Scartezzini JL. Bi-directional transmission properties of Venetian blinds: experimental assessment compared to ray-tracing calculations. Solar Energy. 2005;78:187-98.

[99] Andersen M, Rubin M, Scartezzini J-L. Comparison between ray-tracing simulations and bi-directional transmission measurements on prismatic glazing. Solar Energy. 2003;74:157-73.

[100] Reinhart C, Andersen M. Development and validation of a Radiance model for a translucent panel. Energy and Buildings. 2006;38:890-904.

[101] Papamichael KM, Klems J, Selkowitz S. Determination and application of bidirectional solar-optical properties of fenesration materials. Technical report LBL-25124. Berkeley: Lawrence Berkeley National Laboratory; 1988.

[102] Klems JH. A new method for predicting the solar heat gain of xomplex fenestration systems. I. Overview and derivation of the matrix layer calculation, . ASHRAE Winter Meeting New Orleans, LA1994.

[103] Klems JH, Warner JL. Measurement of bidirectional optical properties of complex shading devices. ASHRAE Transactions. 1995;101:791-801. 
[104] Klems JH, Warner JL, Kelley GO. A comparison between calculated and measured SHGC for complex glazing systems. ASHRAE Transactions. 1997;102:931-9.

[105] Apian-Bennewitz P, Hardt Jvd. Enhancing and calibrating a goniophotometer. Solar Energy Materials and Solar Cells. 1998;54:309-22.

[106] J. Breitenbach, S L, Langle I, Rosenfeld JLJ. Optical and thermal performance of glazing with integral venetian blinds. Energy and Buildings. 2001;33:433-42.

[107] Apian-Bennewitz P. pab gonio-photometer ii.

[108] Kostal H, Kreysar D, Rykowski R. WHITE PAPER: Application of Imaging Sphere for BSDF Measurements of Arbitrary Materials. 2013.

[109] Boer Jd. Numerical Goniophotometer, User Manual. Fraunhofer Institute of Building Physics, Stuttgart2004.

[110] G. Ward, R. Shakespeare. Rendering with Radiance: The Art and Science of Lighting Visualization, Revised Edition: BookSurge, LLC; 2004.

[111] McNeil A, Jonsson CJ, Appelfeld D, Ward G, Lee ES. A validation of a ray-tracing tool used to generate bi-directional scattering distribution functions for complex fenestration systems. Solar Energy. 2013;98:404-14.

[112] Sun Y, Wu Y, Wilson R. Analysis of the daylight performance of a glazing system with Parallel Slat Transparent Insulation Material (PS-TIM). Energy and Buildings. 2017;139:616-33.

[113] SHC. Daylight in Buidling. In: Kjeld John, Watkins R, editors. ECBCS Annex 29/ SHC Task 21 Project Summary Report. Hertfordshire, United Kingdom2010.

[114] Pellegrino A. Traditional and new metrics for effective daylighting design. Advanced Builidng Skins, Energy Forum. Bressanone, Italy2013.

[115] Wienold J. Dynamic daylight glare evaluation. . Builing simulation 2009 the 11th international IBOSA conference. Glasgow, UK2009. p. 44-51.

[116] Wienold J. Dynamic simulation of blind control strategies for visual comfort and energy balance analysis. . Building simulation 2007, the 10th international IBOSA conference. Beijing, China2007. p. 1197-204.

[117] Nabil A, Mardaljevic J. Useful daylight illuminances: A replacement for daylight factors. Energy and Buildings. 2006;38:905-13.

[118] M. Saxena, G. Ward, T. Perry, L. Heschong, R. Higa. Dynamic RADIANCE Predicting annual daylight with variable fenestratio optics using BSDFs. Fourth National Conference of IBPSA-USA. New York City, USA2010.

[119] Reinhart C, Herkel S. The simulation of annual daylight illuminance distributions - a state-of-the-art comparison of six RADIANCE-based methods. Energy and Buildings. 2000;32:167-87.

[120] Reinhart C, Walkenhorst O. Validation of dynamic RADIANCE-based daylight simulations for a test office with external blinds. Energy and Buildings. 2001;33:683-97.

[121] Bellia L, Pedace A, Fragliasso F. The role of weather data files in Climate-based Daylight Modeling. Solar Energy. 2015;112:169-82.

[122] Hiyama K, Wen L. Rapid response surface creation method to optimize window geometry using dynamic daylighting simulation and energy simulation. Energy and Buildings. 2015;107:417-23.

[123] Li L, Qu M, Peng S. Performance evaluation of building integrated solar thermal shading system: Building energy consumption and daylight provision. Energy and Buildings. 2016;113:189-201.

[124] Bellia L, Pedace A, Fragliasso F. The impact of the software's choice on dynamic daylight simulations' results: A comparison between Daysim and 3ds Max Design ${ }^{\circledR}$. Solar Energy. 2015;122:249-63. 
[125] Bellia L, Pedace A, Fragliasso F. Dynamic daylight simulations: Impact of weather file's choice. Solar Energy. 2015;117:224-35.

[126] Mangkuto RA, Rohmah M, Asri AD. Design optimisation for window size, orientation, and wall reflectance with regard to various daylight metrics and lighting energy demand: A case study of buildings in the tropics. Applied Energy. 2016;164:211-9.

[127] Kapsis K, Dermardiros V, Athienitis AK. Daylight Performance of Perimeter Office Façades utilizing Semi-transparent Photovoltaic Windows: A Simulation Study. Energy Procedia. 2015;78:334-9.

[128] Moon P, Spencer D. Illumination from a Nonuniform Sky. Illuminating Engineering. 1942;37:707-26.

[129] Institution BS. Lighting for Buildings--Part 2: Code of Pratice for Daylight. British Standard BS8206. London: BSI; 1992.

[130] IESNA. IESNA Lighting Handbook, 9th ed. New York: Illuminating Engineering Society of North America; 2000.

[131] Construction PsRoCMo. Chinese Standard for daylight design of building. GB/T 50033- 2001. Beijing: China Building Industry Press; 2001.

[132] Li DHW, Tsang EKW. An analysis of daylighting performance for office buildings in Hong Kong. Building and Environment. 2008;43:1446-58.

[133] CF. Reinhart. Daylight performance predictions. In: Jan L.M. Hensen, Lamberts R, editors. Building performance simulation for design and operation London: Spon Press; 2011. [134] Du J, Sharples S. Assessing and predicting average daylight factors of adjoining spaces in atrium buildings under overcast sky. Building and Environment. 2011;46:2142-52.

[135] Lim Y-W, Kandar MZ, Ahmad MH, Ossen DR, Abdullah AM. Building façade design for daylighting quality in typical government office building. Building and Environment. 2012;57:194-204.

[136] USGBC. LEED-NC (leadership in energy and environmental design) version 3.0. 2006. p. www.usgbc.org/LEED/.

[137] Acosta I, Munoz C, Campano MA, Navarro J. Analysis of daylight factors and energy saving allowed by windows under overcast sky conditions. Renewable Energy. 2015;77:194207.

[138] Fasi MA, Budaiwi IM. Energy performance of windows in office buildings considering daylight integration and visual comfort in hot climates. Energy and Buildings. 2015;108:30716.

[139] C.F. Reinhart OW. Dynamic radiance-based daylight simulations for a full-scale test office with outer venetian blinds. Energy \& Buildings. 2001;33:683-97.

[140] Reinhart C, Weissman D. The daylit area - Correlating architectural student assessments with current and emerging daylight availability metrics. Building and Environment. 2012;50:155-64.

[141] Saxena M, Heschong L, Van DenWymelenberg K, Wayland S. 61 Flavors of daylight. the ACEEE Summer study on energy efficiency in buildings. Asilomar, CA, USA: American council for an energy-efficient economy; 2010.

[142] Reinhart C, Rakha T, Weismann D. Predicting the daylit area: a comparison of students assessments and simulations at eleven schools of architecture. Leukos. 2014;10:193-206.

[143] IESNA. LM-83-12 IES Spatial Daylight Autonomy (sDA) and Annual Sunlight Exposure (ASE). New Yourk: NY; 2012.

[144] Reinhart C, Mardaljevic J, Rogers Z. Dynamic daylight performance metrics for sustainable buidling design. Leukos. 2006;3:1-25.

[145] Rogers Z. Daylighting Metric Development Using Daylight Autonomy Calculations in the Sensor Placement Optimization Tool. Boulder, Colorado, USA: Architectural Energy Corporation.; 2006. 
[146] Mardaljevic J. Daylight design, simulation and compliance for solar building envelopes. Energy Forum. Bressanone, Italy2013.

[147] Mardaljevic J, Heschong L, Lee E. Daylight metrics and energy saving. Lighting Research + Technology. 2009;41:261-83.

[148] Berardi U, Anaraki HK. Analysis of the Impacts of Light Shelves on the Useful Daylight Illuminance in Office Buildings in Toronto. Energy Procedia. 2015;78:1793-8.

[149] Franks M. Daylight in Museums. International Radiance Workshops2005.

[150] Wienold J, Christoffersen J. Evaluation methods and development of a new glare prediction model for daylight environments with the use of CCD cameras. Energy and Buildings. 2006;38:743-57.

[151] Ochoa CE, Aries MBC, van Loenen EJ, Hensen JLM. Considerations on design optimization criteria for windows providing low energy consumption and high visual comfort. Applied Energy. 2012;95:238-45.

[152] CIBSE. Guide A - Environmental Design. 7 ed. London: CIBSE Publications; 2006.

[153] BRE. BREEAM Hea 1:Visual comfort. London2014.

[154] Gong J, Kostro A, Motamed A, Schueler A. Potential advantages of a multifunctional complex fenestration system with embedded micro-mirrors in daylighting. Solar Energy. 2016;139:412-25.

[155] Gagne JML, Andersen M, Norford LK. An interactive expert system for daylighting design exploration. Building and Environment. 2011;46:2351-64.

[156] Andersen M, Gagne JML, Kleindienst S. Interactive expert support for early stage fullyear daylighting design: A user's perspective on Lightsolve. Automation in Construction. 2013;35:338-52.

[157] Andersen M. Unweaving the human response in daylighting design. Building and Environment. 2015;91:101-17.

[158] <DIALux_evo-_New_calculation_method.pdf>.

[159] Kazanasmaz T. Fuzzy logic model to classify effectiveness of daylighting in an office with a movable blind system. Building and Environment. 2013;69:22-34.

[160] Acosta I, Muñoz C, Esquivias P, Moreno D, Navarro J. Analysis of the accuracy of the sky component calculation in daylighting simulation programs. Solar Energy. 2015;119:5467.

[161] Yun G, Yoon KC, Kim KS. The influence of shading control strategies on the visual comfort and energy demand of office buildings. Energy and Buildings. 2014;84:70-85.

[162] Fernandes LL, Lee ES, McNeil A, Jonsson JC, Nouidui T, Pang X, et al. Angular selective window systems: Assessment of technical potential for energy savings. Energy and Buildings. 2015;90:188-206.

[163] Hoffmann S, Lee ES, McNeil A, Fernandes L, Vidanovic D, Thanachareonkit A. Balancing daylight, glare, and energy-efficiency goals: An evaluation of exterior coplanar shading systems using complex fenestration modeling tools. Energy and Buildings. 2016;112:279-98.

[164] Shameri MA, Alghoul MA, Elayeb O, Zain MFM, Alrubaih MS, Amir H, et al. Daylighting characterstics of existing double-skin façade office buildings. Energy and Buildings. 2013;59:279-86.

[165] Chen Y, Liu J, Pei J, Cao X, Chen Q, Jiang Y. Experimental and simulation study on the performance of daylighting in an industrial building and its energy saving potential. Energy and Buildings. 2014;73:184-91.

[166] Reinhart C, Fitz A. Findings from a survey on the current use of daylight simulations in building design. Energy and Buildings. 2006;38:824-35.

[167] Jacobs A. UNIX for RADIANCE Tutorail. 
[168] Reinhart C, Pierre-Felix B. Experimental validation of autodesk® 3ds max® design 2009 and daysim 3.0. LEUKOS - Journal of Illuminating Engineering Society of North America. 2009;6:7-35.

[169] Wong IL. A review of daylighting design and implementation in buildings. Renewable and Sustainable Energy Reviews. 2017;74:959-68.

[170] Mardaljevic J. Validation of a lighting simulation program: a study using measured sky brightness distributions, Lux, . The Eighth European Lighting Conference,. Amsterdam1997. p. 555-69.

[171] Jacobs A. Radiance Tutorial. http://www.jaloxa.eu/resources/radiance/documentation/docs/radiance tutorial.pdf2012.

[172] Crawley DB, Hand JW, Kummert M, Griffith BT. Contrasting the capabilities of building energy performance simulation programs. Building and Environment. 2008;43:66173.

[173] Loonen RCGM, Favoino F, Hensen JLM, Overend M. Review of current status, requirements and opportunities for building performance simulation of adaptive facades. Journal of Building Performance Simulation. 2016:1-19.

[174] EnergyPlus. EnergyPlus EMS Application Guide. 2015.

[175] Yoon YB, Kim DS, Lee KH. Detailed heat balance analysis of the thermal load variations depending on the blind location and glazing type. Energy and Buildings. 2014;75:84-95.

[176] Firląg S, Yazdanian M, Curcija C, Kohler C, Vidanovic S, Hart R, et al. Control algorithms for dynamic windows for residential buildings. Energy and Buildings. 2015;109:157-73.

[177] Sun Y, Liang R, Wu Y, Wilson R, Rutherford P. Glazing systems with Parallel Slats Transparent Insulation Material (PS-TIM): Evaluation of building energy and daylight performance. Energy and Buildings. 2018;159:213-27. 